\title{
Neural Stem Cell Transplantation Induces Stroke Recovery by Upregulating Glutamate Transporter GLT-1 in Astrocytes
}

\author{
๑Darco Bacigaluppi, ${ }^{1}$-Gianluca Luigi Russo, ${ }^{1 \star}$-Luca Peruzzotti-Jametti, ${ }^{1 \star}$ Silvia Rossi, ${ }^{3}$ Stefano Sandrone, ${ }^{1}$ \\ Erica Butti, ${ }^{1}$ Roberta De Ceglia, ${ }^{1}$ Andrea Bergamaschi, ${ }^{1}$ Caterina Motta, ${ }^{\circledR}{ }^{\circledR}$ Mattia Gallizioli, ${ }^{1}$ OValeria Studer, ${ }^{3}$ \\ Emanuela Colombo, ${ }^{1}$ Cinthia Farina, ${ }^{1}$ Giancarlo Comi, ${ }^{1}$ - Letterio Salvatore Politi, ${ }^{2}$ Luca Muzio, ${ }^{1}$ @Claudia Villani, ${ }^{4}$ \\ @Roberto William Invernizzi, ${ }^{4}$ Dirk Matthias Hermann, ${ }^{5 \dagger}$ Diego Centonze,,${ }^{3,6 \dagger}$ and @Gianvito Martino ${ }^{1}$ \\ ${ }^{1}$ Neuroimmunology Unit, Institute of Experimental Neurology and ${ }^{2}$ Neuroradiology Unit, Division of Neuroscience, San Raffaele Scientific Institute and \\ Vita Salute San Raffaele University, 20132 Milan, Italy, ${ }^{3}$ Department of Systems Medicine, Tor Vergata University, 00133 Rome, Italy, ${ }^{4}$ Neurochemistry and \\ Behavior, IRCCS-Istituto di Ricerche Farmacologiche "Mario Negri," 20156 Milan, Italy, 5Department of Neurology, University Hospital, D-45122 Essen, \\ Germany, and 'Unit of Neurology and of Neurorehabilitation, IRCCS Neuromed, 86077 Pozzilli (IS), Italy
}

Ischemic stroke is the leading cause of disability, but effective therapies are currently widely lacking. Recovery from stroke is very much dependent on the possibility to develop treatments able to both halt the neurodegenerative process as well as to foster adaptive tissue plasticity. Here we show that ischemic mice treated with neural precursor cell (NPC) transplantation had on neurophysiological analysis, early after treatment, reduced presynaptic release of glutamate within the ipsilesional corticospinal tract (CST), and an enhanced NMDAmediated excitatory transmission in the contralesional CST. Concurrently, NPC-treated mice displayed a reduced CST degeneration, increased axonal rewiring, and augmented dendritic arborization, resulting in long-term functional amelioration persisting up to $60 \mathrm{~d}$ after ischemia. The enhanced functional and structural plasticity relied on the capacity of transplanted NPCs to localize in the periischemic and ischemic area, to promote the upregulation of the glial glutamate transporter 1 (GLT-1) on astrocytes and to reduce peri-ischemic extracellular glutamate. The upregulation of GLT-1 induced by transplanted NPCs was found to rely on the secretion of VEGF by NPCs. Blocking VEGF during the first week after stroke reduced GLT-1 upregulation as well as long-term behavioral recovery in NPC-treated mice. Our results show that NPC transplantation, by modulating the excitatory-inhibitory balance and stroke microenvironment, is a promising therapy to ameliorate disability, to promote tissue recovery and plasticity processes after stroke.

Key words: ischemia; neurophysiology; plasticity; recovery; stem cell; transplantation

Significance Statement

Tissue damage and loss of function occurring after stroke can be constrained by fostering plasticity processes of the brain. Over the past years, stem cell transplantation for repair of the CNS has received increasing interest, although underlying mechanism remain elusive. We here show that neural stem/precursor cell transplantation after ischemic stroke is able to foster axonal rewiring and dendritic plasticity and to induce long-term functional recovery. The observed therapeutic effect of neural precursor cells seems to underlie their capacity to upregulate the glial glutamate transporter on astrocytes through the vascular endothelial growth factor inducing favorable changes in the electrical and molecular stroke microenvironment. Cell-based approaches able to influence plasticity seem particularly suited to favor poststroke recovery.

\section{Introduction}

Ischemic stroke perturbs functional neuronal networks but also elicits spontaneous compensatory proregenerative mechanisms defined as adaptive plasticity (Murphy and Corbett, 2009). Stroke recovery mechanisms are based on structural and functional changes in brain circuits recapitulating patterns of devel-

\footnotetext{
Received May 18, 2016; revised Aug. 4, 2016; accepted Aug. 9, 2016.

Author contributions: M.B., C.F., G.C., R.W.I., D.M.H., D.C., and G.M. designed research; M.B., G.L.R., L.P.-J., S.R., S.S., E.B., R.D.C., A.B., C.M., M.G., V.S., E.C., L.S.P., L.M., and C.V. performed research; M.B., G.L.R., L.P.-J., S.R., S.S., C.V., R.W.I., and D.C. analyzed data; M.B., G.L.R., L.P.-J., S.R., and G.M. wrote the paper.

This work was supported in part by TargetBrain (EU Framework 7 project HEALTH-F2-2012-279017), NEUROKINE network (EU Framework 7 ITN project), and Ricerca Finalizzata GR-2011-02348160. We thank D. De Feo, A. Merlini, and C. Taveggia for critical comments and corrections; E. Brambilla for technical support; and the Advanced Light and Electron Microscopy Biolmaging Center, San Raffaele Scientific Institute.
}

The authors declare no competing financial interests.

This article is freely available online through the J Neurosci Author Open Choice option.

*G.L.R. and L.P.-J. contributed equally to this work.

tD.M.H. and D.C. contributed equally to this work.

Correspondence should be addressed to either Dr. Gianvito Martino or Marco Bacigaluppi, Institute of Experimental Neurology, Division of Neuroscience, San Raffaele Scientific Institute, Via Olgettina 58, 20132 Milan, Italy. E-mail: martino.gianvito@hsr.it or bacigaluppi.marco@hsr.it. 
opment of the nervous system and experience-dependent plasticity. However, these spontaneous processes, which mainly take place in unaffected brain areas, are often insufficient to promote recovery of neurological functions (Murphy and Corbett, 2009). The ideal successful treatment strategy for postischemic disability would inhibit excitotoxicity and at the same time regulate the excitatory-inhibitory transmitter release to foster compensatory neuronal networks (Centonze et al., 2007; Bavelier et al., 2010; Cheng et al., 2014). However, in stroke, also glial cells, reputed to remove excitatory neurotransmitters and electrolytes from the extracellular space, thus controlling neuronal excitability and enabling synaptic plasticity become dysfunctional (Pannasch et al., 2011; Hermann and Chopp, 2012). Excitatory amino acid transporters (EAATs), in particular the glutamate aspartate transporter (GLAST, EAAT1), the glial glutamate transporter 1 (GLT-1, EAAT2), and the excitatory amino-acid carrier 1 (EAAC1, EAAT3), are expressed by glial, endothelial, and neuronal cells. By removing excess of glutamate, EAATs play a crucial role in terminating the excitatory signal loop, in maintaining the homeostatic tissue balance (Takasaki et al., 2008), and in promoting synaptic plasticity processes (Yu et al., 2013). The dysfunction and deregulation of these transporters are a pathogenic mechanisms shared by several neurological disorders, such as stroke, amyotrophic lateral sclerosis (Rao et al., 2001; Lepore et al., 2008), epilepsy (Tanaka et al., 1997; Proper et al., 2002), and Alzheimer disease (Masliah et al., 2001). In particular in experimental stroke, the expression of GLT-1 in glial cells is significantly altered in the peri-ischemic area (Rao et al., 2001; Ouyang et al., 2007), and the failure, reversal of functioning, or reduced expression of this transporter exacerbates the excitotoxicity (Tanaka et al., 1997). Interestingly, a polymorphism in the EAAT2 promoter, leading to higher plasma glutamate concentrations, has been associated with a higher frequency of nonresolving progressive human stroke (Mallolas et al., 2006).

Neural stem cell transplantation has been proposed in recent years as promising therapy to relieve stroke disability. While diverse mechanism have been proposed that might also underlie the different source of stem cell, the route and timing of transplantation used, no conclusive data concerning the cellular and molecular mechanisms sustaining the neural precursor cell (NPC)-mediated therapeutic effects in vivo are available. In particular, whether or not these cells contribute to stroke recovery by changing the electrical and/or molecular stroke microenvironment, directly or via local production of soluble molecules (in one or both hemispheres), is still unclear (Martino et al., 2011). Understanding the mechanisms underlying the therapeutic potential of stem cells is very relevant to unravel and develop new efficacious therapeutic targets.

The objectives of the present study were twofold: (1) to explore whether transplanted NPCs are able to influence functional and structural plasticity after stroke; and (2) to understand and possibly characterize the mechanisms by which transplanted NPCs modify the microenvironment and promote poststroke recovery.

We here found that delayed intravenous transplantation of NPCs in mice after middle cerebral artery occlusion (MCAO) dampens ischemia-induced changes in the ipsilesional hemi-

DOI:10.1523/JNEUROSCI.1643-16.2016

Copyright $\odot 2016$ Bacigaluppi et al.

This is an Open Access article distributed under the terms of the Creative Commons Attribution License Creative Commons Attribution 4.0 International, which permits unrestricted use, distribution and reproduction in any medium provided that the original work is properly attributed. sphere and promotes contralesional adaptive plasticity by upregulating GLT-1 in the peri-ischemic area. Transplanted NPCs, which are selectively located within the lesion and within perilesional brain areas, contribute to tone down excitatory neuronal networks by the reduction of extracellular glutamate. Indeed, transplanted NPCs promote brain plasticity and poststroke recovery by increasing the expression of GLT-1 on endogenous astrocytes, located within the peri-ischemic area, and through the secretion of VEGF.

Our work highlights how neural stem cell transplantation, which can differentially modulate the excitatory balance between ipsilesional and contralesional hemispheres, can promote poststroke recovery.

\section{Materials and Methods}

Study approval and animals. Adult male C57bl/6 mice (8-10 weeks old) were purchased from Charles River. Experimental procedures, performed in a blinded fashion for treatment, were approved by the Institutional Animal Care and Use Committee (no. 419 and 581) at Scientific Institute, Ospedale San Raffaele Milano (Italy). Mice underwent 45 min left MCAO, as described previously (Bacigaluppi et al., 2009). Briefly, animals were anesthetized with $1-1.5 \%$ isofluorane (Merial) in $30 \% \mathrm{O}_{2}$. Temperature was maintained between $36.5^{\circ} \mathrm{C}$ and $37.0^{\circ} \mathrm{C}$, and laser Doppler flow was monitored. Focal cerebral ischemia of the MCA was induced with a silicon-coated (Xantopren, Bayer Dental) 8-0 nylon filament (Ethilon, Ethicon). At $72 \mathrm{~h}$ after ischemia, animals were randomized into two treatment groups: one receiving an intravenous transplantation of $10^{6}$ GFP-labeled NPC (NPC-treated) and the other being transplanted with vehicle solution (sham-treated).

NPC preparation and transplantation. NPCs were obtained from 6-week-old C57bl/6 mice, as previously described (Pluchino et al., 2008). NPCs at passage number $\leq 15$ were used in all experiments. All cells used were tested and were negative for mycoplasma. At time of cell transplantation (Bacigaluppi et al., 2009), single cell-dissociated GFP ${ }^{+}$labeled (80-90\% upon lentiviral infection) NPCs $\left(1 \times 10^{6}\right.$ cells in $400 \mu \mathrm{l} 0.1 \mathrm{M}$ PBS) were injected into the tail vein. Sham-treated mice were injected with $400 \mu \mathrm{l}$ of $0.1 \mathrm{~m}$ PBS.

To block GLT-1 in vivo, mice were intrastriatally ( $0 \mathrm{~mm}$ anterioposterior and $1.6 \mathrm{~mm}$ mediolateral) injected with either dihydrokainic acid (at a dose of $30 \mu \mathrm{g} / \mathrm{mouse} / \mathrm{d}$ ) in sterile PBS (Tocris Bioscience, 0111 ) or with PBS alone via a brain catheter (Brain infusion Kit 3, ALZET) connected to a subcutaneously implanted osmotic minipump (ALZET, model 1007) (Domercq et al., 2005) for $7 \mathrm{~d}$.

To determine the quantity of VEGF, $10 \mathrm{~d}$ after NPC or sham treatment, ischemic mice were anesthetized, perfused with saline, and the ischemic and the contralesional hemisphere microdissected. Tissue was weighted and homogenized in $200 \mu \mathrm{l}$ of a lysis solution containing Tris $\mathrm{HCl}, \mathrm{pH} 7.4(50 \mathrm{~mm})$ and inhibitor of proteases (Sigma, 100×) in $\mathrm{ddH}_{2} \mathrm{O}$. Samples were frozen, thawed, and centrifuged for $10 \mathrm{~min}$ at $10,000 \times g$ at $4^{\circ} \mathrm{C}$. The supernatants were collected and tested by ELISA kit (Mouse VEGF DuoSet, catalog \#493, R\&D Systems) to determine VEGF level. Protein values were normalized to the weight of the tissue in milligrams.

To study the effect of VEGF in inducing in vivo GLT-1 or GLAST expression, adult male mice received a $2 \mu \mathrm{l}$ stereotaxic injection of mouse VEGF-A (R\&D Systems, $493 \mathrm{mV}$ ) in the left striatum and PBS in the right striatum. To in vivo neutralize VEGF, mice intrastriatally (see above) received a neutralizing antibody against VEGF-A (Leaf purified antimouse VEGF-A Ab, clone 2G11-2A05, catalog \#512808, Biolegend) or control isotype (Ultra-Leaf purified Rat IgG2a, K isotype, clone RTK2758, catalog \#400544, Biolegend) at a dose of $7 \mu \mathrm{g} / \mathrm{mouse} / \mathrm{d}$ via a brain catheter (Brain infusion Kit 3, ALZET) connected to a subcutaneously osmotic minipump (ALZET, model 1007), for $7 \mathrm{~d}$ before analyses or other treatments.

Behavioral analyses. The modified Neurological Severity Score (mNSS) and grip strength of the paretic forepaw (measured using a Newtonmeter, Medio-Line Spring Scale, metric, 300 g, Pesola), were 
evaluated as previously described (Bacigaluppi et al., 2009). Behavioral tests were performed by a researcher blinded to the treatment group during the light phase of the circadian cycle beginning $4 \mathrm{~h}$ after lights on.

Analysis of infarct size. For the measurement of the ischemic lesion volume, coronal $20-\mu \mathrm{m}$-thick cryostat brain sections were prepared from $2 \mathrm{~mm}$ rostral to $4 \mathrm{~mm}$ caudal to the bregma. One systematic random series of sections per mouse was stained for cresyl violet (Sigma), digitalized and analyzed with ImageJ (National Institutes of Health) image analysis system. The lesion area (either total or striatal) was measured for each reference level by the "indirect method," as previously described (Butti et al., 2012). For the representative 3D volume rendering images (see Figs. $1 C, 5 A$ ), a representative brain either stained by cresyl violet (see Fig. 1C) or for transplanted $\mathrm{GFP}^{+}$NPCs (see Fig. 5A) was traced using the assistance of the Stereo Investigator version 3.0 software (MicroBrightField) and a personal computer running the software connected to a color video camera mounted on a Leica microscope as described previously (West et al., 1991; Butti et al., 2012).

Tissue pathology. On the day of death, animals were weighted, deeply anesthetized, and transcardially perfused with $25 \mathrm{ml}$ of saline phosphate buffer (PBS: $0.1 \mathrm{M}, \mathrm{pH} 7.2$ ) with EDTA, followed by $25 \mathrm{ml}$ PFA (4\% in PBS). Brains were carefully dissected, postfixed overnight, cryoprotected in sucrose, and embedded in tissue-freezing medium for cryostat sectioning. Frozen brains were cut into 20 - to $50-\mu \mathrm{m}$-thick coronal cryostat sections. Spinal cords were cut into $30 \mu \mathrm{m}$ axial cryostat sections.

Assessment of corticospinal tract integrity. Degenerating corticospinal tract (CST) fibers were assessed by immunofluorescence for c-amyloid precursor protein (rabbit anti-cAPP, Sigma) (Andres et al., 2011). For quantitative analysis of APP-immunoreactive axons, 3 sequential axial cervical spinal cord sections $\sim 300 \mu \mathrm{m}$ apart were selected from each animal. Axonal loss of the lesioned dorsal CST was measured by staining cervical spinal cord sections for Bielschowsky at $60 \mathrm{~d}$ post treatment (dpt). Stained sections were digitalized using the $20 \times$ objective of an Olympus microscope and a CCD camera, and analyzed with ImageJ (National Institutes of Health) image analysis software. The ratio of the area of the ipsilesional and contralesional cervical CST for each section and an average ratio per mouse were calculated.

Dendritic analysis. Mice were anesthetized and killed at $60 \mathrm{dpt}$. Brains were removed and coronal sections brain slices (60 $\mu \mathrm{m}$ thick) in the region 1 and $-1 \mathrm{~mm}$ from bregma were stained using the Rapid GolgiStainTM Kit (FD NeuroTechnologies). Cortical layer V pyramidal neurons of the left (ispilesional, close to the ischemic lesion) and respective site in the right motor cortex were analyzed by an investigator blinded to the treatment groups. Traced neurons were selected on the basis of the classic pyramidal morphology consisting of a triangularly shaped cell body, vertically oriented spiny apical dendrite, and laterally oriented basilar dendrites. Criteria for inclusion in the analyses were as follows: (1) the neuron had to be well impregnated; (2) fully visible, namely, not obscured neither obstructed by overlapping blood vessels, astrocytes, or other dendrites; and (3) with intact dendritic arborization that should be visible in the plane of section. Moreover, both the apical and basilar branches had not to display any obvious signs of degeneration, such as beading of the primary apical dendrite, which would obscure visualization and quantification of the spines, and both the apical and basilar trees had to be complete, with no broken or missing branches (Corbett et al., 2006; Papadopoulos et al., 2006; Brown et al., 2008; Andres et al., 2011). The first 4 neurons from cortical layer $\mathrm{V}$ in each hemisphere of 4 animals per group that were fitting the above criteria were reconstructed in three dimensions using Neurolucida software (Andres et al., 2011) by following the dendrites all through the $z$-axis (Coleman and Riesen, 1968). The length of each dendritic branch and spines was determined using the measuring tool on the StereoInvestigator software (MicroBrightField). Sholl and Branch analyses were then performed on the traced neurons.

Assessment of axonal plasticity. Mice were injected at $45 \mathrm{dpt}$ with biotin dextran amine (BDA; 10,000 molecular weight, Invitrogen, diluted in $0.01 \mathrm{M} \mathrm{PB}$ at $\mathrm{pH} 7.4$ ) over the contralateral motor cortex, and the tracer was allowed to diffuse along the axons for 2 weeks before death ( $60 \mathrm{dpt})$, as described previously (Reitmeir et al., 2012). We evaluated the number of tracer-stained fibers at two levels: in the cerebral peduncle at the level of the red nucleus ( $-2.70 \mathrm{~mm} ;-3.95 \mathrm{~mm}$ from bregma) and in the CST [at the level of the cervical enlargement (C4-C6)] on two sections collected at a distance of $250 \mu \mathrm{m}$. Labeled fiber density using virtual isotropic hemispherical probes (radius: $22 \mathrm{~mm}$ ) on the Stereo Investigator version 3.0 software (MicroBrightField) were counted using Neurolucida version 5.0 and Stereo Investigator version 3.0 software (MicroBrightField Biosciences). Fiber counts were examined using a $100 \times$ objective (Carl Zeiss), and the average thickness of each section was determined manually. By measuring the total area of the cerebral peduncle and CST using Neurolucida, we then calculated the overall density of labeled pyramidal tract fibers. Corticorubral projections were evaluated at the level of the red nucleus $(-2.70 \mathrm{~mm} ;-3.95 \mathrm{~mm}$ from bregma). A $500-\mu \mathrm{m}$-long intersection line was superimposed on the brain midline. Fibers crossing into the ipsilesional side were counted at the level of the cervical spinal cord enlargement (C4-C6). An 800- $\mu \mathrm{m}$-long intersection line was superimposed on the cervical spinal cord midline. Fibers crossing into the ipsilesional spinal hemicord were quantified. One of every fifth section (for a total of three sections per site) was evaluated. The total number of counted crossing fibers per section per level was divided by the assessed area (section thickness $X$ used line length), thus obtaining a fiber density. Fiber densities determined at the red nucleus were normalized with the total number of labeled cerebral peduncle fibers, whereas crossing fibers at the level of the cervical enlargement were normalized with the total number of labeled CST fibers.

Characterization of transplanted NPCs. Brain sections were stained using previously published immunofluorescence protocols (Pluchino et al., 2005; Bacigaluppi et al., 2009). To analyze the accumulation and distribution of transplanted NPCs within the brain, GFP ${ }^{+}$NPCs (chicken anti-GFP, 1:1000, Abcam) were quantified on coronal brain sections (bregma $2 \mathrm{~mm} ;-4 \mathrm{~mm}$ ). The number of cells per section and plane was multiplied by the number of sections in between the levels, thus obtaining overall numbers of $\mathrm{GFP}^{+}$NPCs per brain. This number was then used to calculate the number of transplanted cells per $\mathrm{mm}^{3}$ of brain tissue. The following primary antibodies were otherwise used: rabbit anti-ALDH1L1 (1:250, Abcam), rabbit anti-aquaporin 4 (1:100, Sigma); rabbit anti-III- $\beta$-tubulin (1:500, Covance); rabbit anti-BDNF $(1: 100$, Millipore Bioscience Research Reagents); rabbit anti- DARPP-32 (1:200, Abcam); mouse anti-NeuN (1:500, Millipore); mouse anti-PSA-NCAM (1:500, Millipore Bioscience Research Reagents); goat anti-CNTF (1:100, Abcam); rat anti-F4/80 (1:200, Abcam); rat anti-CD31 (1:100; BD Pharmingen); rabbit anti-GFAP (1:500; Dako); rabbit anti-VEGF (1:50; R\&D Systems); and goat anti-doublecortin (1:100, Santa Cruz Biotechnology). Nuclei were stained with DAPI (Roche). The reconstructions shown in Figure $5 C$ has been obtained by automatically mosaicking multiple images using the Leica confocal microscope TCS SP8.

GLT-1 and GLAST expression assessment in the peri-ischemic area. For GLT-1 and GLAST quantification, serial coronal brain sections at 3, 10, and $30 \mathrm{dpt}$ stained for GLT-1 (guinea pig anti-GLT-1, 1:100 Millipore) or GLAST (rabbit anti-GLAST, 1:200, Abcam) were evaluated. Microphotographs were taken with a CCD camera along the ischemic border with a $40 \times$ magnification. Mean fluorescence intensity of each microphotograph was evaluated with ImageJ (National Institutes of Health) software and then averaged. The reconstructions shown in Figure $6 E$ have been made with Adobe Photoshop CC out of $n=14$ adjacent images on $12-\mu \mathrm{m}$-thick sections of a representative individual MCAO mouse either sham-treated or NPC-treated and killed at $10 \mathrm{dpt}$.

Neurophysiological patch-clamp recordings. Ex vivo electrophysiological analysis following MCAO and treatment or sham surgery by wholecell patch-clamp recordings of medium spiny neurons (MSNs) on acute brain slices ( $\geq 15$ neurons per experimental condition per side) at $10 \mathrm{dpt}$ were performed as described previously (Centonze et al., 2007; Butti et al., 2012). Corticostriatal slices $(200 \mu \mathrm{m})$ were acutely prepared from tissue blocks of the brain (Rossi et al., 2006). The slices used were located from $(1.5 ;-1.5 \mathrm{~mm})$ anterior-posterior, to bregma. Slices were cut along the interhemispheric line, and slices from a single hemisphere (either ischemic or contralesional) were transferred to a recording chamber and submerged in a continuously flowing aCSF $\left(35^{\circ} \mathrm{C}, 2-3 \mathrm{ml} / \mathrm{min}\right)$ gassed with $95 \% \mathrm{O}_{2}-5 \% \mathrm{CO}_{2}$. Striatal spiny neurons were clamped at $-80 \mathrm{mV}$, close to their respective resting membrane potentials. 
In MCAO mice, recordings were performed from striatal neurons of the peri-ischemic zone, defined as the first visible neuron when the objective of the microscope was moved from the center of the ischemic region toward the periphery. Whole-cell access resistances measured in voltage-clamp were in the range of $10-20 \mathrm{M} \Omega$ before electronic compensation $(60-80 \%$ was routinely used). Striatal spiny neurons were clamped at $-80 \mathrm{mV}$, close to their respective resting membrane potentials. Spontaneous GABA-mediated IPSCs (sIPSCs) were recorded from striatal neurons in the presence of CNQX (Tocris-Cookson) and MK-801 maleate (MK-801, Tocris-Cookson), to block AMPA and NMDA receptors, respectively. Spontaneous glutamate-mediated EPSCs (sEPSCs) were recorded from striatal neurons in the presence of bicuculline-methiodide (Sigma) to block $\mathrm{GABA}_{\mathrm{A}}$ receptors. sIPSCs and sEPSCs were stored by using pClamp 8 (Molecular Devices) and analyzed off line on a personal computer with Mini Analysis 5.1 (Synaptosoft) software. Offline analysis was performed on spontaneous synaptic events recorded during a fixed time epoch $(2-3 \mathrm{~min})$, sampled every $2 \mathrm{~min}$ (10-12 samplings). Only cells exhibiting stable sPSC frequencies $(<20 \%$ changes during the control samplings) were taken into account. For sEPSC kinetic analysis, events with peak amplitude between 10 and $50 \mathrm{pA}$ were grouped, aligned by half-rise time, and normalized by peak amplitude to obtain rise times, decay times, and half-widths. Events with complex peaks were eliminated. Drugs were applied by dissolving them to the desired final concentration in the Krebs solution and by switching the perfusion from control solution to drug-containing; values are reported as mean \pm SEM.

To test the NMDAR/AMPAR ratio, a bipolar stimulating electrode was located intrastriatally, close to the recording electrode $(50-150 \mu \mathrm{m})$, to evoke glutamate-mediated synaptic currents [evoked EPSCs, (eEPSCs)] in MSNs, in the continuous presence of picrotoxin ( $50 \mu \mathrm{M}$; from SigmaAldrich), with internal solution containing the following (in $\mathrm{mM}$ ): 120 Cs- $\mathrm{MeSO}_{3}, 15 \mathrm{CsCl}, 8 \mathrm{NaCl}, 0.2$ EGTA, 10 HEPES, $2 \mathrm{Mg}$-ATP, $0.3 \mathrm{Na}$ GTP, 10 tetraethylammonium, and 5 QX-314. Stimuli were delivered at $0.1 \mathrm{~Hz}$. For the NMDAR/AMPAR ratio experiments, neurons were voltage-clamped at -70 and $40 \mathrm{mV}$ to record, respectively, AMPARmediated and NMDAR-mediated EPSCs. The AMPA EPSC component was obtained by subtracting the baseline current value from the peak current value. NMDA EPSC component was identified by using the kinetic method, considering the peak amplitude at $50 \mathrm{~ms}$ after the beginning of the event. The NMDAR/AMPAR ratio was calculated by dividing the NMDAR peak by the AMPAR peak (Paillé et al., 2010).

In vivo microdialysis. Sham- and NPC-treated mice were implanted at 9 dpt with microdialysis probes in the ipsilesional striatum for the in vivo measurement of extracellular glutamate. Concentric dialysis probes were prepared with Cuprophan membrane 3-mm-long, $216 \mu \mathrm{m}$ outer diameter, 3000 Da cutoff (Sorin Biomedica) (Invernizzi et al., 2013) and implanted, in ketamine/xylazine-anesthesized animals, at the stereotaxic coordinates (in $\mathrm{mm}$ from bregma and dura surface) (Paxinos and Franklin, 2000): striatum anteroposterior 0.2 , left 2.0 and ventral 4.2. Approximately $24 \mathrm{~h}$ after surgery, in vivo microdialysis was performed on conscious freely moving mice. Probes were perfused with aCSF (composition in mM as follows: $145 \mathrm{NaCl}$, $1.26 \mathrm{CaCl}_{2}, 3 \mathrm{KCl}, 1 \mathrm{MgCl}_{2}, 1.4 \mathrm{Na}_{2} \mathrm{HPO}_{4}, \mathrm{pH} 7.4$ with $0.6 \mathrm{M} \mathrm{NaH}_{2} \mathrm{PO}_{4}$ ) at 2 $\mu \mathrm{l} / \mathrm{min}$, using a CMA/100 pump (CMA/Microdialysis). After $1 \mathrm{~h}$ of washout, baseline levels of glutamate were measured by collecting perfusate every $10 \mathrm{~min}$ for $60 \mathrm{~min}$ and then analyzed by high-performance liquid chromatography with fluorometric detection after precolumn derivatization with o-phthalaldehyde-based reagent as described previously (Ceglia et al., 2004).

NPCs to astrocyte transwell cocultures. Cortical astrocyte cultures were prepared from P2 mouse whole brain using Neural Tissue Dissociation Kits (MACS Miltenyi Biotec) and cultured as described previously (Colombo et al., 2012). Transwell chambers ( $3 \mu \mathrm{m}$ pore Millipore) were used to physically separate the astrocytes from NPCs. Coculture experiments between $3 \times 10^{5}$ NPCs and mature astrocytes $\left(5 \times 10^{4}\right)$ in astrocyte medium were performed also using the PI3 kinase inhibitor, 2-(4morpholinyl)-8-phenyl-4H-1-benzopyran-4-one (LY294002, Calbiochem) $500 \mathrm{~nm}$. To assess GLT-1 and GLAST overexpression on astrocytes, we treated 50,000 astrocytes in a 24 well plates with recombinant mouse VEGF 165 (Peprotech) for $24 \mathrm{~h}$ or the coculture of NPC with astrocytes with VEGF receptor inhibitor (500 nM, VEGFR2 kinase inhibitor IV, Calbiochem).

After coculture or after factor addition, cells were harvested for RT-PCR while the collected medium was used for ELISA assays (mouseVEGFa, -EGF, PDGF-BB, -TGFb, from R\&D Systems) according to the manufacturer's protocol.

For immunoblot analysis, astrocytes or striatal tissue were lysed by frosting and defrosting in lysis buffer (containing Tris $\mathrm{HCl} 0.2 \mathrm{M}, \mathrm{pH} 8$, and Protease Inhibitor $1 \times$, Sigma) and centrifuged at $10,000 \times g$ for 10 min at $4^{\circ} \mathrm{C}$ as described previously (Petr et al., 2015): mouse anti- $\beta$-actin (1:15000; Santa Cruz Biotechnologies); mouse anti-EAAT2/GLT-1 (1: 1000; Millipore clone G6); and rabbit anti-EAAT1/GLAST (1:500; Abcam). Western blots were quantified measuring optical densities of immunoreactive protein bands (in vitro only monomer of GLT-1 was present) using ImageJ or Image Laboratory (Bio-Rad Laboratories) software, normalizing results to $\beta$-actin values.

$R T-P C R$. Quantitative RT-PCR was performed using predeveloped TaqMan Assay Reagents on an ABI Prism 7500 Sequence Detection System (Applied Biosystems) according to manufacturer's protocol. Total RNA was isolated using the RNeasy Micro Kit (\#74004; QIAGEN) according to the manufacturer's instructions, including DNase digestion. At the end, RNA samples were eluted from columns using $20 \mu \mathrm{l}$ of RNase-free water, and their concentrations were determined spectrophotometrically by A260 (Nanodrop-ND1000). The cDNA was synthesized from 100 to $500 \mathrm{ng}$ of total RNA using the Thermo Script RT-PCR (Invitrogen, 11146-024). Approximately $25 \mathrm{ng}$ of cDNA was used for RT-PCR using predesigned TaqMan Gene Expression Assays (Applied Biosystems) on an ABI Prism 7500 Sequence Detection System (Applied Biosystems). GAPDH was used as housekeeping gene.

Statistical analysis. Data were evaluated by unpaired $t$ tests (for comparisons between 2 groups) or by one-way ANOVA followed by post hoc analyses (for comparison between $\geq 3$ groups) as indicated in the figure legends. The significance level was established at $p \leq 0.05$. Kruskal-Wallis test followed by Mann-Whitney test was used in case of nonparametric data. To test the treatment effect on each of the behavior scores, behavioral tests were evaluated by means of repeated-measures ANOVA. Whenever a treatment $\times$ time interaction or treatment effect was present at the 0.05 level, a post hoc analysis was done by Bonferroni post hoc test. A standard software package (GraphPad Prism version 5.00f) was used.

\section{Results}

\section{NPC transplantation promotes postischemic recovery}

To determine the therapeutic effect of NPCs in postacute ischemic stroke, mice subjected to $45 \mathrm{~min}$ transient MCAO were intravenously transplanted with $10^{6} \mathrm{NPCs}$ (NPC-treated) or vehicle solution alone (sham-treated) $3 \mathrm{~d}$ after stroke onset (Fig. $1 A)$. Significant reductions in motor force, balance, and coordination skills were observed in animals exposed to MCAO. In sham-treated ischemic animals, disability at the grip strength test and mNSS (investigating motor, sensory, and balance capacities) remained almost unchanged over the entire observation period of $60 \mathrm{dpt}$. Conversely, animals treated with NPCs displayed progressive improvement of motor force and mNSS. (Fig. 1B). Quantification of the lesion volume at $60 \mathrm{dpt}$ showed a small reduction in NPC-treated mice, although no overt effect on brain atrophy reduction (Fig. 1C). Also, the lesion volume of the striatum was reduced in NPC-compared with sham-treated animals $\left(6.3 \pm 0.26\right.$ and $4.0 \pm 0.09 \mathrm{~mm}^{3}$ for sham-treated and NPC-treated mice, respectively, $p \leq 0.01)$. Because the CST crosses the middle cerebral artery territory, which is affected by the ischemia, we next analyzed how NPC treatment would influence CST degeneration and plasticity. At $60 \mathrm{dpt}$, NPCtreated mice showed a reduced axonal degeneration of the ipsilesional CST area and fewer C-terminal amyloid precursor protein (cAPP, a marker of impaired axonal transport and 


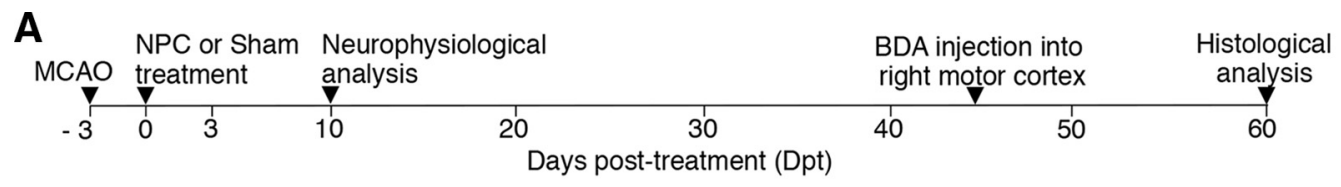

B
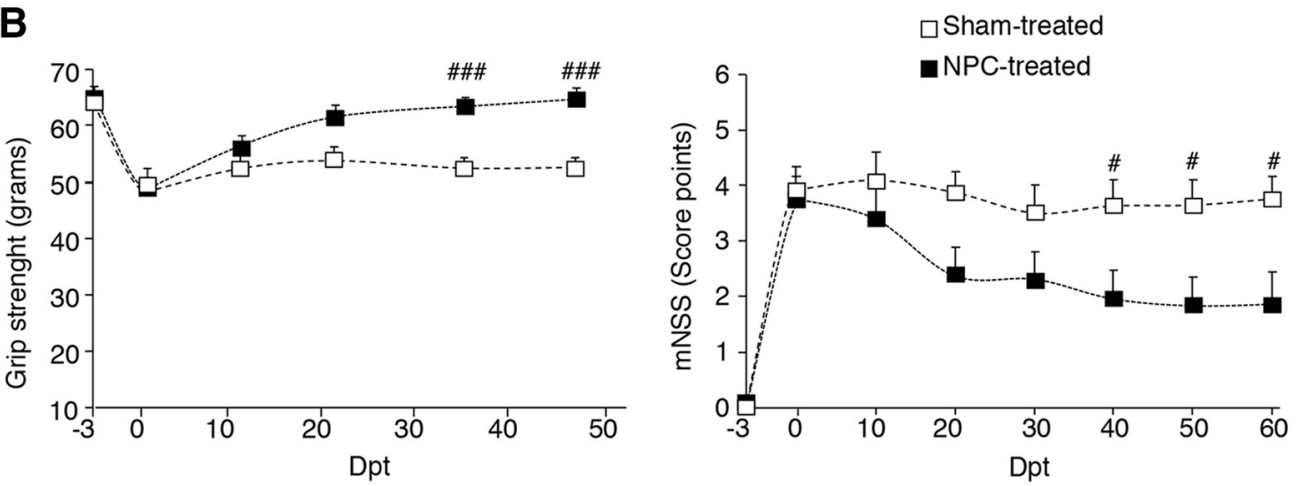

C
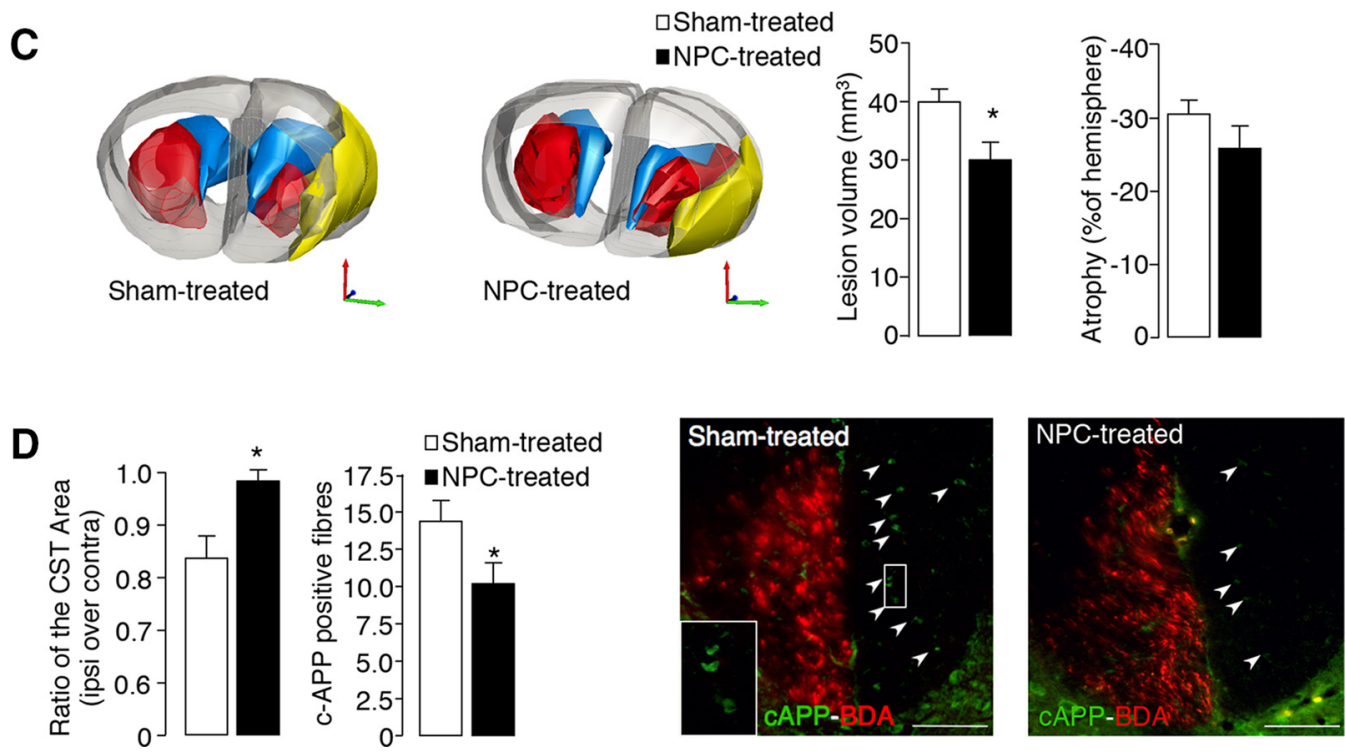

Figure 1. NPC treatment promotes postischemic neurological recovery and tissue protection. $\boldsymbol{A}$, Experimental study design. $\boldsymbol{B}$, Grip strength test of the right paretic forepaw and mNSS of sham-treated (white) and NPC-treated mice (black); $n=8$ or 9 mice/group. C, Representative serial 3D reconstructions of the brains of a sham- and an NPC-treated mouse at 60 dpt. Yellow represents the ischemic lesion. Red represents the healthy striatum. Blue represents the lateral ventricles. Gray represents the contours of the hemispheres. Graphs on right represent the lesion volume (in $\mathrm{mm}^{3}$ ) and the atrophy of the ipsilesional hemisphere (as percentage of the contralateral hemisphere) ( $n=4$ or 5 mice/group). $\boldsymbol{D}$, Quantification of the (ST area evaluated on Bielschowsky-stained sections at level C4-C6 at $60 \mathrm{dpt}$ (left) and quantification of the number of C-APP ${ }^{+}$fibers in the ipsilesional CST at cervical spinal cord level (C4-C6) at 60 dpt in NPC-treated mice (right) ( $n=4$ mice/group). Representative microphotographs of a sham- and a NPC-treated mouse show c-APP ${ }^{+}$fibers (green, arrowheads) of the ipsilesional CST, whereas the contralesional CST is denoted by the BDA (red; injected in the contralesional CST). Inset, Magnification showing c-APP ${ }^{+}$fibers. Scale bar, $50 \mu \mathrm{m}$. Data are mean \pm SEM. ${ }^{\#} p \leq 0.05$ (two-way ANOVA, Bonferroni post hoc test). ${ }^{\# \#} \leq 0.001$ (two-way ANOVA, Bonferroni post hoc test). ${ }^{*} p \leq 0.05$, unpaired $t$ test.

degeneration) positive axons at the level of the cervical spinal cord (Fig. 1D).

We then investigated whether the neurological improvement slowly developing over time in NPC-treated mice could be due to enhanced cortical and axonal plasticity in addition to CST preservation. We analyzed pyramidal cells in layer $\mathrm{V}$ of the cerebral cortex because they give rise to the CST. At $60 \mathrm{dpt}$, Golgi staining (Fig. 2A) in NPC-treated mice showed an increase of the dendritic length of pyramidal neurons in layer $\mathrm{V}$ of the ipsilesional and contralesional motor cortex ( $p \leq 0.05$; Fig. $2 B$ ). Dendritic spine length was found to be increased both for the analyzed ipsilesional pyramidal neurons $(1.478 \pm 0.066$ and $1.744 \pm 0.087$ $\mu \mathrm{m}$, sham- vs NPC-treated, $p \leq 0.05, t$ test) as well as for contralesional pyramidal neurons $(1.558 \pm 0.083,1.874 \pm 0.089 \mu \mathrm{m}$, sham- vs NPC-treated, $p \leq 0.05, t$ test) after NPC treatment. To further evaluate the contralateral CST contribution to recovery processes, an anterograde axonal tracer (i.e., BDA, 10,000 MW) was injected in the contralesional motor cortex (Fig. 2C). NPCtreated mice displayed at $60 \mathrm{dpt}$ a higher density of fibers stemming from the contralesional pyramidal tract toward the ipsilesional denervated red nucleus ( $p \leq 0.05$ ). At cervical spinal cord level, the number of crossing fibers originating from the contralesional CST and reinnervating the opposite spinal hemicord was also increased after NPC transplantation ( $p \leq 0.05$ ) (Fig. $2 C$ ).

Together, transplanted NPCs protect the ipsilesional CST from ischemia-induced degeneration and promote dendritic and axonal plasticity.

\section{NPCs rebalance ischemia-induced neurophysiological} alterations

To understand whether the increased recovery observed in NPCtreated mice was preceded by functional changes, a neurophysi- 
A
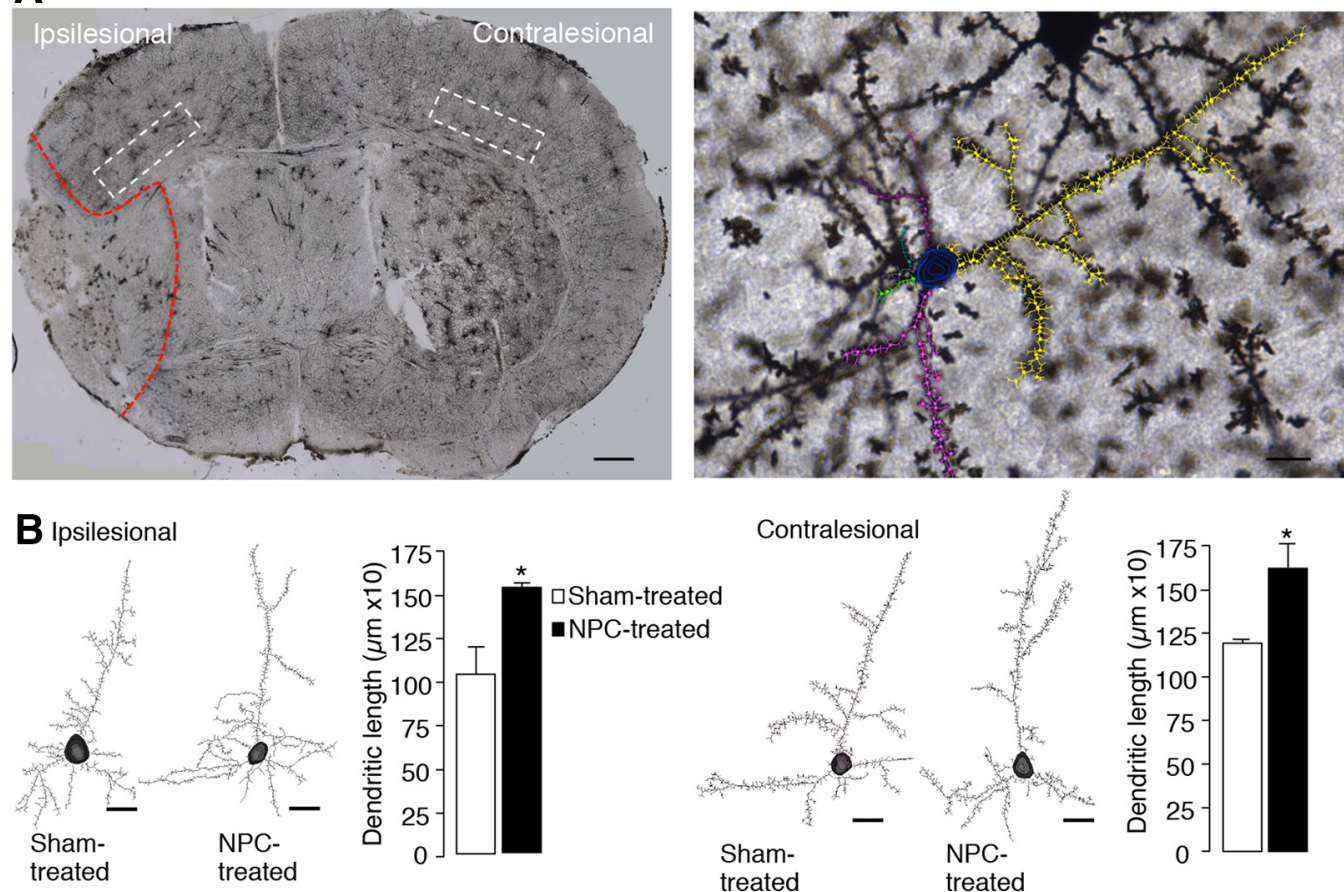

\section{C}
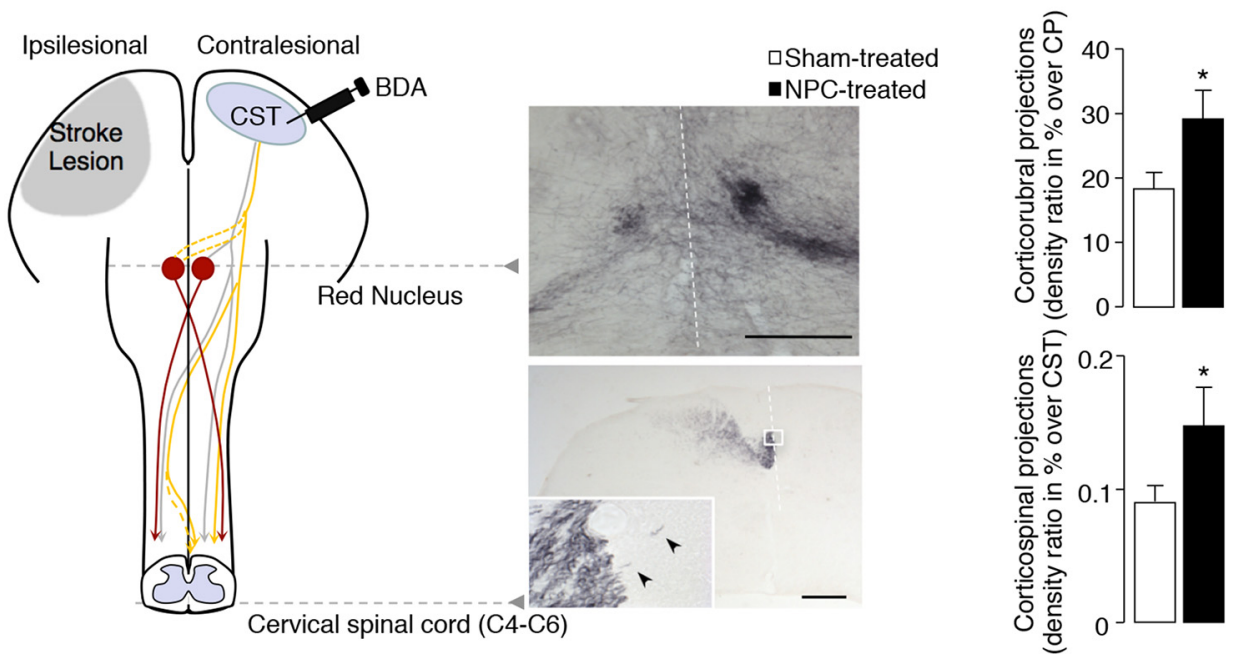

Figure 2. NPC-treated mice display increased dendritic plasticity and contralesional axonal sprouting. $\boldsymbol{A}$, Representative coronal brain section of a Golgi-stained ischemic brain at $60 \mathrm{dpt}$. Red dashed line indicates the boundary of the ischemic lesion. White dashed boxes represent the fifth cortical layer region from which pyramidal neurons have been selected. Scale bar, $500 \mu \mathrm{m}$. Right, The dendritic tree (depicted in colors) of a pyramidal neuron traced by Neurolucida software. Scale bar, $10 \mu \mathrm{m}$. B, Representative reconstructions of Golgi-stained pyramidal neurons of the cortical layer V from sham- and NPC-treated mice at $60 \mathrm{dpt}$ in the ipsilesional (left) and contralesional hemisphere (right). Scale bar, $10 \mu \mathrm{m}$. Graphs represent the integrated dendritic length of pyramidal neurons; $n=4$ mice ( 8 neurons/animal per group). C, Schematic representation of the contralesional CST (gray and yellow lines, the latter with sprouting toward the lesioned side) examined by means of the anterograde tract-tracer BDA, injected into the contralesional motor cortex (left hemisphere). Axonal sproutings crossing the midline were examined at the level of the nucleus ruber (red circle; red represents rubrospinal tracts) and at the level of the cervical spinal cord enlargement C4-C6. Representative microphotographs illustrating BDA-traced corticorubral fibers (top) intersecting the midline (superimposed in white) between both red nuclei. Corticospinal fibers (bottom), at cervical spinal cord level (C4 -C6), with fibers crossing the midline, are indicated by arrowheads in the magnified inset. Intersecting lines (white dashed lines) indicate the site where crossing fiber density was analyzed. Scale bars: top, $50 \mu \mathrm{m} ;$ bottom, $250 \mu \mathrm{m}$. Right, Graphs represent the quantitative analysis of BDA-labeled midline-crossing fibers at the level of red nucleus and cervical spinal cord ( $n=4-8$ mice/group). $A-C$, White bars represent sham-treated mice. Black bars represent NPC-treated mice. CP, Cortical peduncle. Data are mean \pm SEM. ${ }^{*} p \leq 0.05$ ( $t$ test).

ological analysis was performed at $10 \mathrm{dpt}$, the time when the initial clinical recovery became initially apparent. Because the cortical glutamatergic terminals mainly innervate MSNs and their activity reflects the selective involvement of corticostriatal transmission in the plastic rearrangements taking place after MCAO (Centonze et al., 2007), whole-cell patch-clamp recordings of striatal MSNs were performed. We observed that ischemia per se diminished, in both hemispheres, the frequency and am- plitude of sIPSCs ( $p \leq 0.05)$ (Fig. $3 A, E$, white bars) and enhanced frequency $(p \leq 0.05)$, decay time and half-width of sEPSCs ( $p \leq 0.05$ ) (Fig. $3 B, C, F, G$, white bars) compared with healthy control animals. This is in line with the literature because overactive NMDA receptors of the presynaptic terminal have been proposed to account for increased glutamate release after MCAO (Centonze et al., 2007). In our analysis, activation of NMDA receptors contributed to glutamate events recorded from 

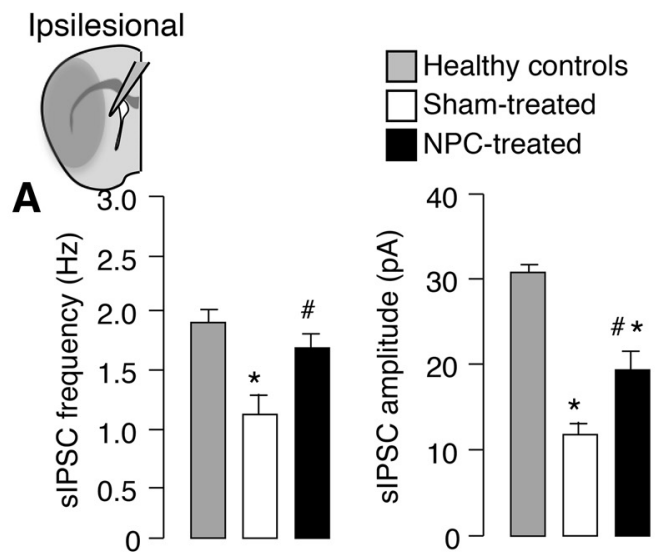

B
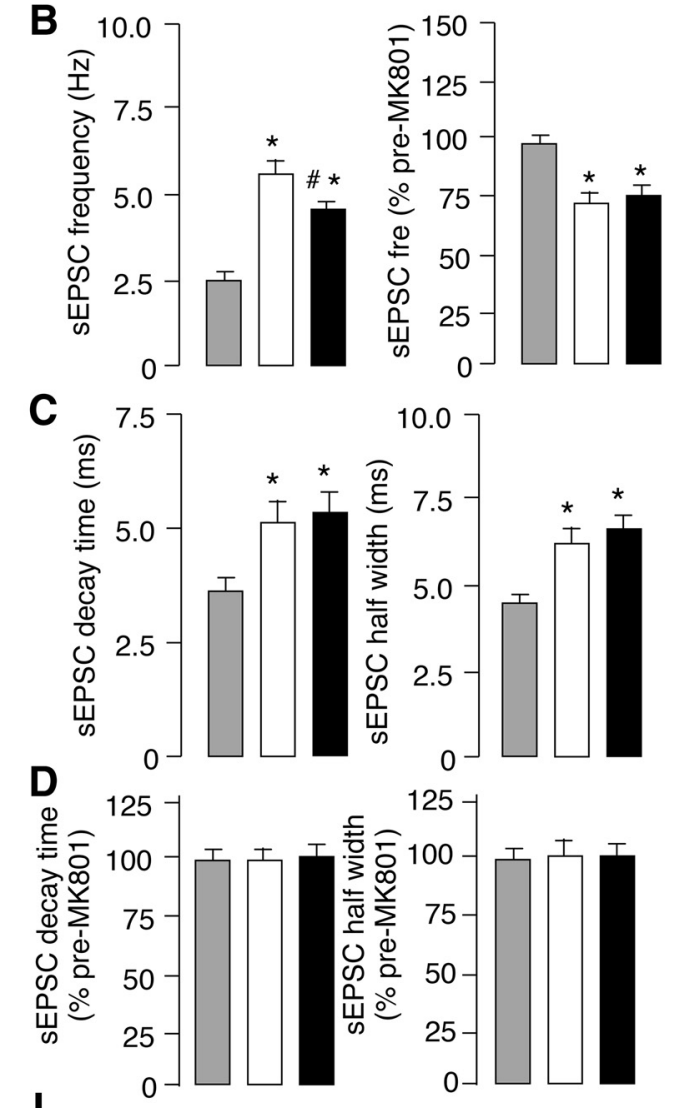

$125-1$
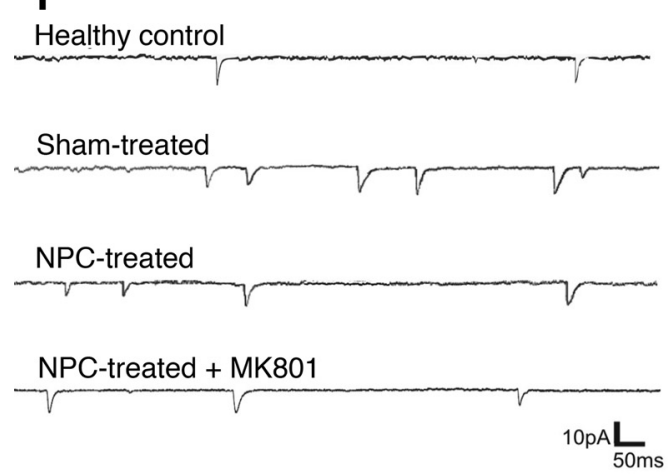
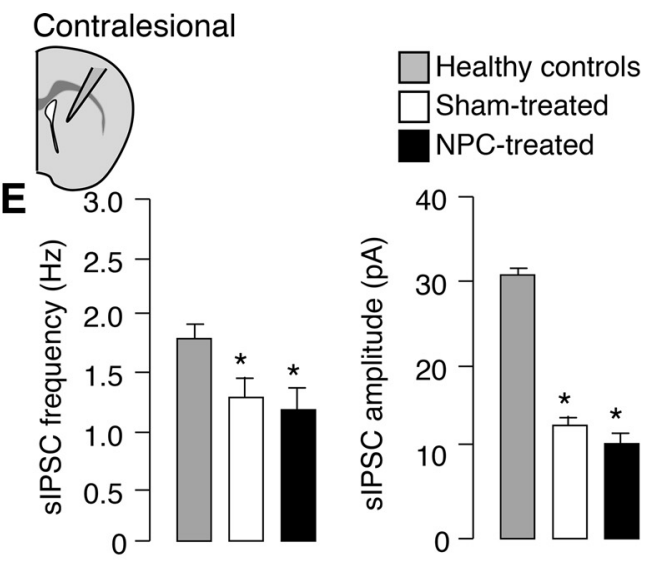

$\mathbf{F}$
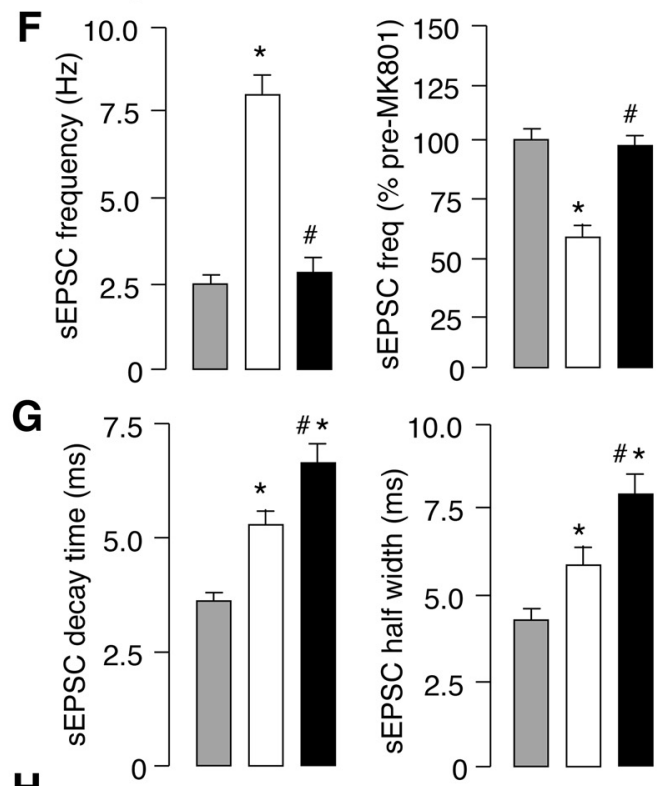

\section{H}

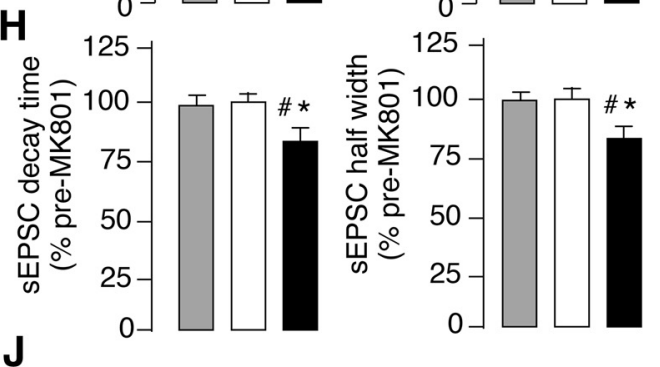

Healthy control

Sham-treated

NPC-treated
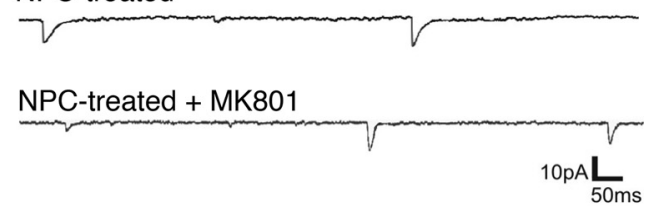

Figure 3. NPC treatment rebalances the ipsilesional inhibitory and excitatory tone and promotes contralesional postsynaptic excitatory currents. Properties of excitatory (E) and inhibitory (I) spontaneous postsynaptic currents (s-PSC) recorded by patch clamp on acute tissue slices from ipsilesional peri-ischemic medium spiny striatal neurons (left panels) and contralesional MSNs (right panels) at $10 \mathrm{dpt}$. In the ipsilesional hemisphere: $\boldsymbol{A}$, Spontaneous IPSC frequency and amplitude are decreased after ischemia. NPC transplantation induces an increase of sIPSCs in the ischemic striatum. $\boldsymbol{B}$, Ipsilesional sEPSC frequency is increased upon ischemia and reduced by NPC treatment. The NMDA antagonist MK-801 reduces sEPSC frequency after MCAO but not in control group. NPC transplantation has no effect on overactive NMDA receptors. $\boldsymbol{C}, \boldsymbol{D}, \mathrm{NPC}$ transplantation has no effect on sEPSC kinetic properties. In the contralesional hemisphere: $\boldsymbol{E}$, NPC transplantation has no effect on sIPSCS compared with sham-treated mice. Nevertheless, NPC transplantation reduces presynaptic sEPSCS $(\boldsymbol{F})$ and potentiates NMDA-dependent postsynaptic (Figure legend continues.) 
striatal neurons after MCAO, as the NMDA antagonist MK-801 significantly reduced $\mathrm{sEPSC}$ frequency $(p \leq 0.05 \mathrm{re}-$ spect to predrug values) (Fig. $3 B$ ). Conversely, MK-801 failed to normalize sEPSC decay time $(p \geq 0.05)$ and halfwidth ( $p \geq 0.05$ ) (Fig. 3D) after MCAO, strongly suggesting the involvement of non-NMDA receptors. A postsynaptic enhancement of AMPA receptor-mediated transmission has been previously described in experimental stroke (Centonze et al., 2007). Application of CNQX, an AMPA receptor antagonist, totally suppressed sEPSCs in healthy control mice, whereas coapplication of MK-801 and CNQX was required to fully suppress $s E P-$ SCs in MCAO mice (data not shown).

Interestingly, NPC-treated mice had an augmented sIPSC frequency and amplitude and a reduced sEPSC frequency in the ipsilesional ischemic striatum compared with sham-treated mice $(p \leq 0.05)$ (Fig. 3A, B, black bars). The enhanced sIPSC was paralleled by an increased survival of DARPP32 ${ }^{+}$MSNs in the ipsilesional striatum of NPCtreated mice at $10 \mathrm{dpt}(1366 \pm 99.52$ vs $798.3 \pm 182.6$ neurons per section \pm SEM, NPC vs sham-treated mice, respectively, $p \leq$ 0.05 , unpaired $t$ test, $n=3-5$ mice/group), pointing to a possible causal relationship (Centonze et al., 2001; Li et al., 2009). In contrast, the sensitivity of glutamate synapses to MK-801 in NPC-treated mice was similar to that of sham-treated mice, suggesting that the presynaptic NMDA receptors were still overactive (Fig. 3B).

In the contralesional hemisphere of NPC-treated mice, we found not only a normalization of sEPSC frequency, but also an increased decay time and half-width compared with the sham-treated group that was blocked by MK-801 application (Fig. $3 F-H$ ). This NPC-induced postsynaptic enhancement of NMDA-dependent excitatory transmission suggests a contralesional effect on processes of synaptic plasticity.

We thus evaluated synaptic strength by quantifying the relative contribution of AMPARs and NMDARs to the eEPSCs as this measure is an index of experience-dependent plasticity (Ungless et al., 2001; Saal et al., 2003). MSNs in the ipsilesional hemisphere of sham- and NPC-treated mice exhibited reduced NMDAR/ AMPAR ratio compared with healthy controls. However, in MSNs of the contralesional hemisphere, we found an increased NMDAR/AMPAR ratio in NPC-treated mice compared with both sham-treated and healthy controls ( $p \leq 0.05)$, indicating an enhanced synaptic strength (Fig. $4 A, B$ ).

Our neurophysiological recordings indicate that NPC treatment in ischemic mice can restore the ipsilesional balance

(Figure legend continued.) $\mathrm{sEPSCS}(\boldsymbol{G}, \boldsymbol{H}) . \boldsymbol{I}, \boldsymbol{J}$, The electrophysiological traces are examples of SEPSCS (downward deflections) recorded from striatal neurons of a control, a sham-, and a NPC-treated animal in the ipsilesional $(\boldsymbol{I})$ and contralesional $(\boldsymbol{I})$ hemisphere. The effect of MK801 on NPC-treated neurons is shown. Gray bars represent healthy controls. White bars represent sham-treated mice. Black bars represent NPC-treated mice. $n=3$ or 4 mice/group, 4 or 5 neurons /hemisphere. Data are mean \pm SEM. ${ }^{*} p \leq 0.05$ versus healthy controls (one-way ANOVA, Tukey's post hoc test). ${ }^{\#} \leq 0.05$ versus sham-treated mice (one-way ANOVA, Tukey's post hoc test). between excitatory and inhibitory currents and can enhance contralateral synaptic strength.

\section{NPCs localize in the peri-infarct area and contribute to reduce extracellular glutamate}

Despite the prominent effect on plasticity processes observed in the contralesional hemisphere, intravenous transplanted NPCs, transduced with the green fluorescent protein $\left(\mathrm{GFP}^{+}\right)$, were found to localize at $10 \mathrm{dpt}$ in the infarct and peri-infarct area $\left(3470 \pm 384\right.$ cells per forebrain, density of $14.5 \pm 1.6$ cell $\left./ \mathrm{mm}^{3}\right)$ and to persist there undifferentiated over time, and up to $60 \mathrm{dpt}$ $\left(2736 \pm 1296\right.$ cells per forebrain, density of $11.4 \pm 5.4$ cells $\left./ \mathrm{mm}^{3}\right)$ (Fig. 5A-G). No transplanted NPCs $\left(\mathrm{GFP}^{+}\right.$cell) were observed in the contralesional hemisphere at any analyzed time-point. The presence of undifferentiated NPCs in the ischemic and periischemic tissue, the amelioration of disability, the increased plasticity processes, and the early neurophysiological observations in NPC-treated mice suggested that these cells might act indirectly modulating the electrical balance between the ischemic and contralateral hemispheres as well as the perilesional microenvironment (Mohajerani et al., 2011).

Because we observed a selective accumulation of NPCs and on neurophysiological analysis a reduction of EPSCs in the ipsilesional hemisphere, we next measured by microdialysis the extracellular levels of glutamate at $10 \mathrm{~d}$ post-transplantation in the ipsilateral striatum of sham- and NPC-treated mice (Fig. 6A). Basal levels of extracellular glutamate were reduced in NPCtreated animals, compared with sham-treated animals $(p \leq 0.05)$ (Fig. $6 B$ ). Together, these data indicate that NPC transplantation is able to operate a reduction of extracellular glutamate levels in the ischemic hemisphere.

\section{Peri-ischemic GLT-1 upregulation in NPC-treated mice is relevant for poststroke recovery}

Because glutamate transporters are important regulators of extracellular levels of glutamate and their derangement upon ischemia is considered one of the reasons for the neurotoxic effect of excessive glutamate release (Tanaka et al., 1997; Rao et al., 2001), 

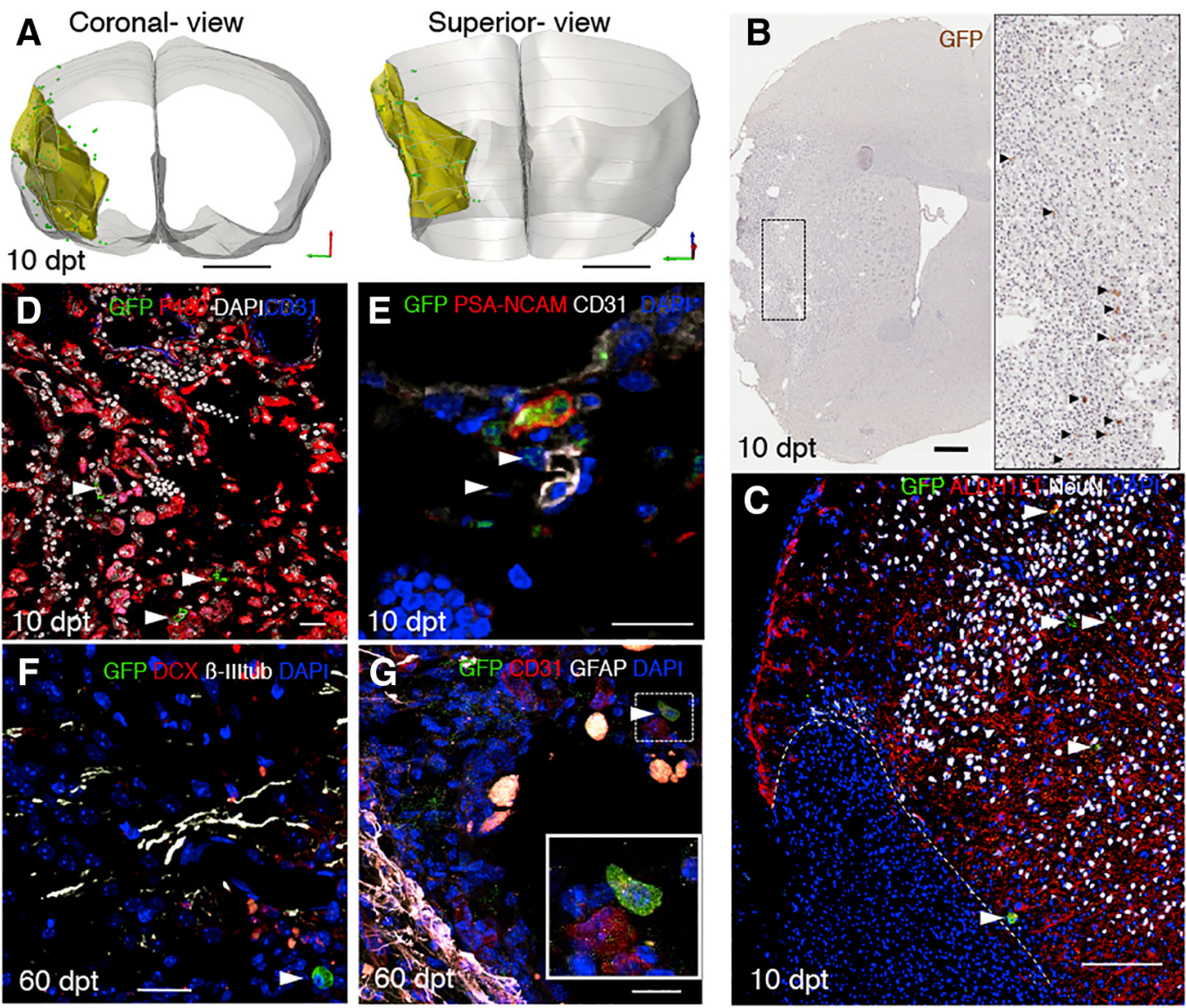

Figure 5. Intravenously transplanted NPCs persist undifferentiated in the ischemic and peri-ischemic tissue. $A$, The distribution of transplanted NPCs localizing in the brain at $10 \mathrm{dpt}$ is shown in the serial 3D brain reconstruction shown in a coronal view and in view from above. Green dots represent GFP ${ }^{+} \mathrm{NPC}$. Yellow represents the ischemic lesion. Gray represents the contours of the hemispheres. $\boldsymbol{B}$, Representative coronal brain section stained for GFP ${ }^{+} \mathrm{NPCs}$ (in brown, highlighted by arrowheads in the magnified inset) showing at $10 \mathrm{dpt}$ the transplanted NPCs localizing within the ischemic and peri-ischemic tissue. Nuclei counterstained by hematoxylin. C, Representative reconstruction displaying the localization of NPCs (GFP ${ }^{+}$in green highlighted by white arrowheads) within the ischemic and peri-ischemic area (lesion border contoured by the dashed white line) in an NPC-treated mice at $10 \mathrm{dpt}$. Astrocytes are labeled by ALDH1L1 (red) and neurons by NeuN (white). Nuclei are counterstained with DAPI (blue). D, G, Representative microphotographs of transplanted NPCs localizing in the ischemic and peri-ischemic tissue. Most of the transplanted NPCs $\left(\mathrm{GFP}^{+}\right.$, green in $\boldsymbol{C}-\boldsymbol{F}$, highlighted by white arrowheads) are found in close contact with inflammatory infiltrates composed of macrophages and microglia $\left(F 4 / 80^{+}\right.$, red in $\left.\boldsymbol{D}\right)$ and in close proximity to $C D 31^{+}$vessels (blue in $\boldsymbol{D}$, white in $\boldsymbol{E}$ ). At $10 \mathrm{dpt}$, transplanted GFP ${ }^{+} \mathrm{NPCs}$ mostly retain an undifferentiated phenotype and show only some neuroblast features (PSA-NCAM ${ }^{+}$, red in $\boldsymbol{E}$ ). Even at $60 \mathrm{dpt}$, most of the $\mathrm{GFP}^{+}$cells mostly exhibit undifferentiated features being negative for $D C X$ (red in $\boldsymbol{F}$ ), for $B$-IIl-tubulin (white in $\boldsymbol{F}$ ), and for GFAP ${ }^{+}$(white in $\boldsymbol{G}$ ). $\boldsymbol{G}$, Dashed box is magnified in the marked contoured inset. Scale bars: $\boldsymbol{A}, 2 \mathrm{~mm} ; \boldsymbol{B}, 500 \mu \mathrm{m} ; \boldsymbol{C}, 200 \mu \mathrm{m} ; \boldsymbol{D}-\mathbf{G}, 20 \mu \mathrm{m}$. Nuclei are counterstained with DAPI (white in $\boldsymbol{D}$, blue in $\boldsymbol{C}, \boldsymbol{E}-\boldsymbol{G}$ ). ALDH1L1, Aldehyde dehydrogenase 1 family member L1; $\beta$-III-tub, $\beta$-III-tubulin; PSA-NCAM, polysialylated neural cell adhesion molecule; CD31 [known also as platelet endothelial cell adhesion molecule (PECAM-1)];DCX, doublecortin; F4/80 [also known as EGF-like module-containing mucin-like hormone receptor-like 1 (EMR1)]; NeuN, neuronal nuclei.

we analyzed glutamate transporter expression in the periischemic tissue of sham-treated and NPC-treated ischemic mice. We observed by immunofluorescence an increased level of GLT-1, but not of GLAST, on peri-ischemic astrocytes of NPCtreated mice at $10 \mathrm{dpt}$ that was also observed by Western blot analysis $(p \leq 0.05)$ (Fig. $6 C-G)$.

To understand the therapeutic significance of the observed NPC-induced increase of GLT-1 in the peri-ischemic area, we selectively inhibited GLT-1 function by implanting, from day 7 to 14 after NPC treatment (the time when neurophysiological and behavioral amelioration take place), a miniosmotic pump for continuous left (peri-ischemic) intrastriatal (IS) delivery of dihydrokainate $\left(\mathrm{DHK}_{\mathrm{IS}}\right)$, an inhibitor of GLT-1 (Pines et al., 1992; Mennerick et al., 1998; Domercq et al., 2005). Dihydrokainate is known to act as a selective inhibitor of the GLT-1 glutamate transporter at low concentration and, at higher concentrations, to be also a weak inhibitor of AMPA/kainate glutamic acid receptors as well (Kidd and Isaac, 2000). We thus used a low dose of DHK to have minimal off-target effects as described by Domercq et al. (2005). While $\mathrm{DHK}_{\mathrm{IS}}$ did not significantly worsen the behavioral outcome of $\mathrm{PBS}_{\mathrm{IS}}$-treated ischemic mice, delivery of $\mathrm{DHK}_{\mathrm{IS}}$ to NPC-treated ischemic mice prevented the behavioral improvement induced by the NPC treatment $\left(\mathrm{PBS}_{\mathrm{IS}}\right.$-treated, NPC-treated) of ischemic mice (Fig. $7 A, B$ ).

On the same group of mice, we also performed patch-clamp analysis to understand whether dihydrokainate treatment was able to reduce at neurophysiological level the effects induced by the NPC treatment. Dihydrokainate treatment induced, per se, on MSNs a decrease in sEPSC frequency in both hemispheres ( $p \leq 0.05$ respect to MCAO), masking an eventual modulation of presynaptic effects of NPCs, while amplitude and kinetic properties were not affected (data not shown). Interestingly, dihydrokainate treatment abolished the postsynaptic enhancement of NMDA-dependent excitatory transmission observed in the contralesional striatum of NPCtreated mice. Consistently, decay time and half-width were not increased in these mice. The NMDA antagonist MK801 did not affect the kinetic properties of sEPSCs recorded from contralesional striatum ( $p \geq 0.05$ respect to predrug values), similarly to nontreated MCAO mice $(p \geq 0.05)$ (Fig. $7 C$ ). 
Together, GLT-1 upregulation in the peri-ischemic tissue seems to be needed for the behavioral recovery and for the contralesional postsynaptic enhancement observed in NPC-treated mice.

\section{VEGF secretion in vitro by NPC is critical for GLT-1 upregulation on astrocytes.}

To understand how transplantation of NPCs modulates GLT-1 expression on astrocytes, we cocultured in vitro NPCs and astrocytes. We specifically used transwells, to evaluate the influence of secreted factors only. Interestingly, we observed selective GLT-1 upregulation $(p \leq 0.05)$ at both transcript and protein level (Fig. $8 A, B$ ) on astrocytes cocultured with NPCs for $24 \mathrm{~h}$. To determine whether growth factors mediate this effect we added LY294002, an inhibitor of the phosphoinositide-3-kinase, to the coculture. Notably, we observed that LY294002 was sufficient to abolish the upregulation of Glt-1 on astrocytes (Fig. 8C). Thus, we screened for growth factors and corresponding receptor gene expression in NPCs and in astrocytes, respectively, in coculturing conditions (Fig. 8D). We quantified those most highly upregulated in the coculture also by performing ELISA quantification on the culture medium. While EGF, PDGF-BB, and TGF- $\beta 1$ were below detection limits (below 3.91, 62.5, and $31.2 \mathrm{pg} /$ $\mathrm{ml}$, respectively), VEGF was highly upregulated upon coculture $(p \leq 0.0001)$ (Fig. $8 E$ ). Accordingly, addition of recombinant VEGF to cultured astrocytes for $24 \mathrm{~h}$ significantly enhanced Glt-1 expression ( $p \leq$ 0.05 ), whereas the use of a selective inhibitor of the VEGF receptor (i-VEGFR) blocked it (Fig. $8 F, G$ ).

\section{VEGF secretion in vivo by NPCs upregulates GLT-1 on astrocytes and mediates poststroke recovery}

Indeed, in vivo, transplanted NPCs localizing at ischemic and peri-ischemic area were found to express VEGF but not CNTF or BDNF (Fig. 9A-C). Increased protein levels of VEGF were also found in the ipsilesional tissue of NPC-treated mice, although we did not observe any VEGF expression diversity in the contralesional hemisphere compared with shamtreated mice $(p \leq 0.05)$ (Fig. 9D). We next verified whether direct injection of VEGF could induce upregulation of Glt-1 in vivo. We thus injected increasing doses of VEGF in the left hemisphere and we found that 100 and 500 pg of VEGF induced a significant increase in Glt-1 expression (Fig. 9E).

Finally, we tested whether inhibition of VEGF released by NPCs could abolish the observed effect of NPCs in stroke. When

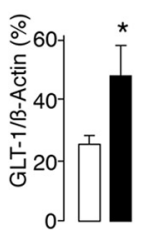

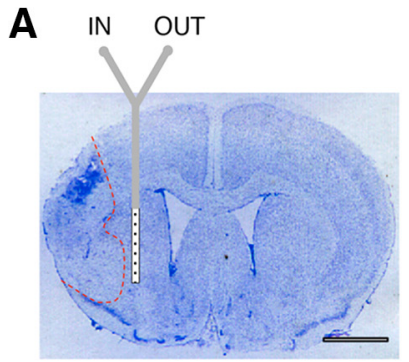

B
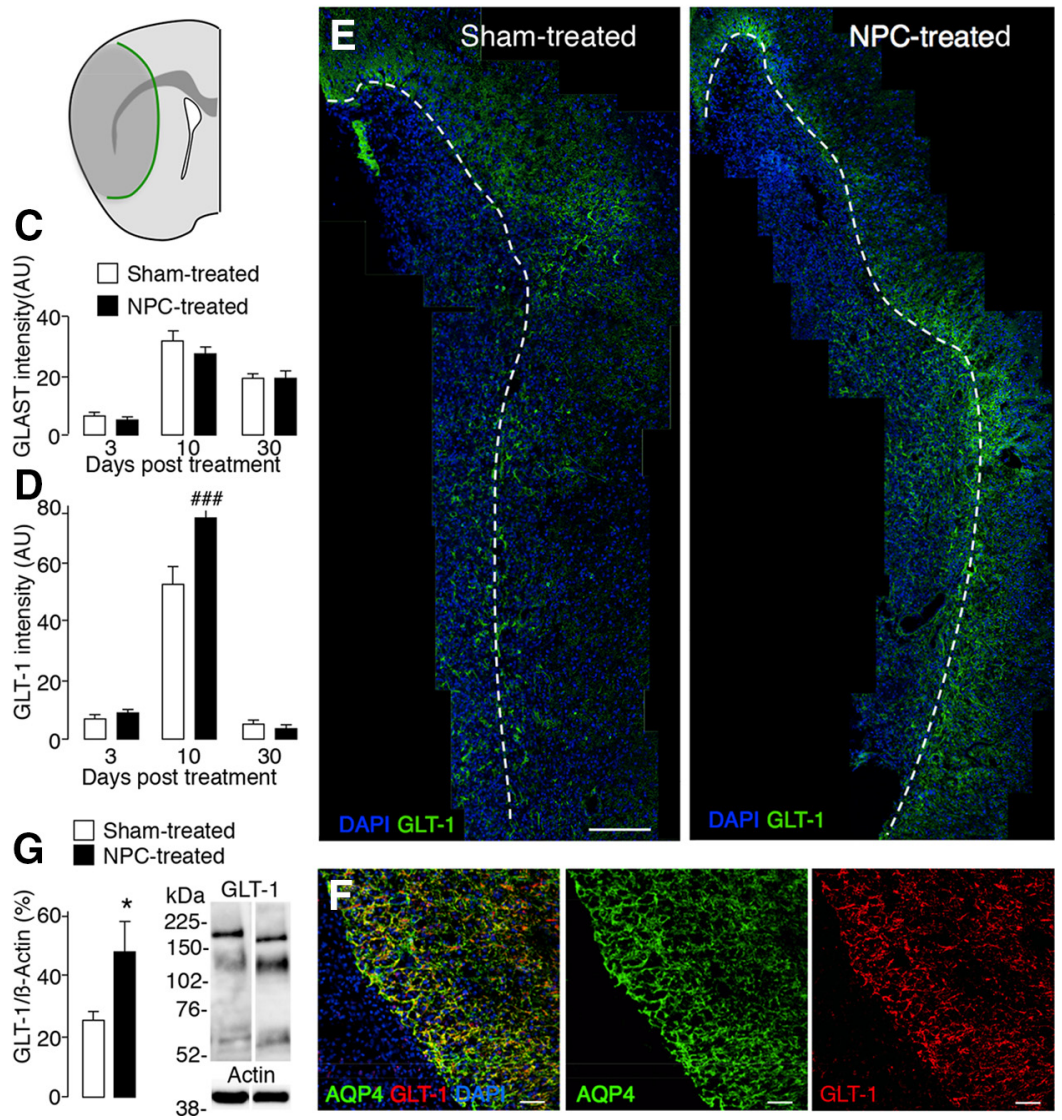

Figure 6. NPC treatment induces functional GLT-1 glutamate transporter upregulation in the peri-ischemic area. $\boldsymbol{A}, \boldsymbol{B}$, In vivo measurement of extracellular glutamate at $10 \mathrm{dpt}$ by a microdialysis probe implanted in the striatum ipsilateral to the ischemic lesion. $\boldsymbol{A}$, Representative cresyl violet-stained coronal ischemic brain section ( $0.2 \mathrm{~mm}$ from bregma) showing a sketched microdialysis probe implanted in the peri-ischemic striatum (ischemic lesion border in red). Note, in particular, the tip of the probe where black and white squares represent the active zone of the dialysis probe. The probe is perfused with either CSF at a rate of $2 \mu \mathrm{l} / \mathrm{min}$ (IN) and the perfusate is collected (OUT) every 10 min for glutamate measurement by high-performance liquid chromatography. Scale bar, $2 \mathrm{~mm}$. $\boldsymbol{B}$, Basal levels of glutamate in shamtreated and NPC-treated mice at $10 \mathrm{dpt}$. Shown is the average basal level of glutamate measured over $60 \mathrm{~min}$ ( $n=6$ or 7 mice per group). ${ }^{*} p \leq 0.05$ ( $t$ test). $\boldsymbol{C}-\boldsymbol{E}$, Quantification of GLAST (C) and GLT-1 (D) expression in the peri-ischemic tissue over time revealed a significant increase of GLT- 1 in NPC-treated animals at $10 \mathrm{dpt}$ ( $n=4-6$ mice /group per time-point). Green line drawn on the schematic ischemic brain hemisphere visualizes the glial border where the quantification has been performed. ${ }^{\# \# \#} p \leq 0.001$ (two-way ANOVA, Bonferronipost hoc test). $\boldsymbol{E}$, Representative reconstructions of the peri-ischemic area (lesion border highlighted by the dashed white line) of a sham-treated and NPC-treated mouse showing the expression of GLT-1 (green) at $10 \mathrm{dpt}$. $\boldsymbol{F}$, Representative immunofluorescence of an ischemic mouse at $10 \mathrm{dpt} \mathrm{showing} \mathrm{GLT-1} \mathrm{expression} \mathrm{(red)} \mathrm{specifically} \mathrm{expressed} \mathrm{on} \mathrm{peri-ischemic} \mathrm{astrocytes,} \mathrm{stained} \mathrm{with} \mathrm{aquaporin} \mathrm{4} \mathrm{(AQP4,} \mathrm{green).} \mathrm{On} \mathrm{the}$ right of the merged image, single colored images (green and red channel) are shown. Nuclei are counterstained with DAPI (blue, $\boldsymbol{E}, \boldsymbol{F}$ ). G, Western blot for GLT-1 in ipsilesional striatum of sham-treated (representative image shown in left lane) and NPC-treated (representative image shown in right lane) mice at $10 \mathrm{dpt}\left(n=4\right.$ mice/group). ${ }^{*} p \leq 0.05$ ( $t$ test). GLT-1 monomer $(\sim 60 \mathrm{kDa})$ and dimer $(\sim 120 \mathrm{kDa})$ were included in the densitometry analysis. Scale bars: $\boldsymbol{E}, 50 \mu \mathrm{m} ; \boldsymbol{F}, 15 \mu \mathrm{m}$. Data are mean \pm SEM. GLU, Glutamate.

we tried to selectively reduce VEGF production in NPCs by infecting the cells with a lentivirus expressing a shRNA construct targeted to VEGF and GFP (Mosher et al., 2012), cell growth was severely impaired, as recently described (Kirby et al., 2015), thus limiting the possibility to prepare VEGF-deficient NPCs to be transplanted (data not shown). We thus tried to inhibit VEGF 


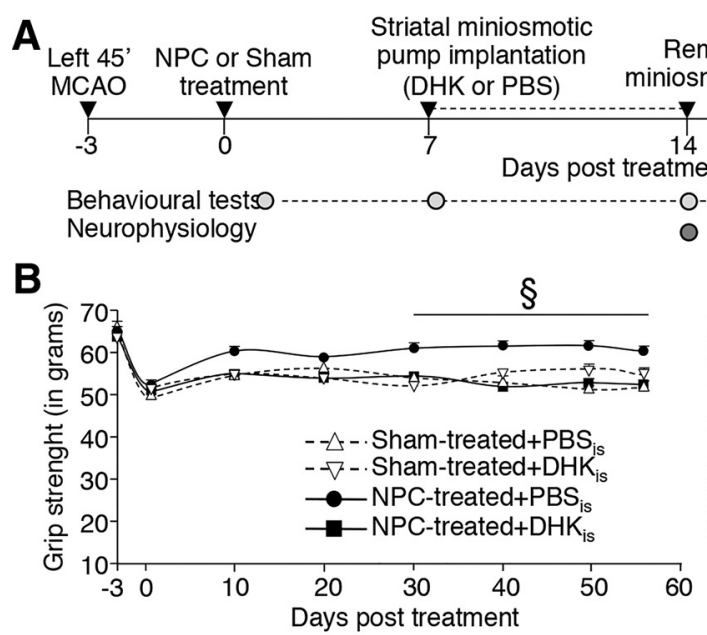

Removal of

iosmotic pump

14 (dpt)

O

-

-

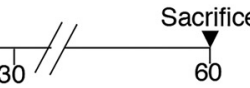

- $/ /$ - - - -
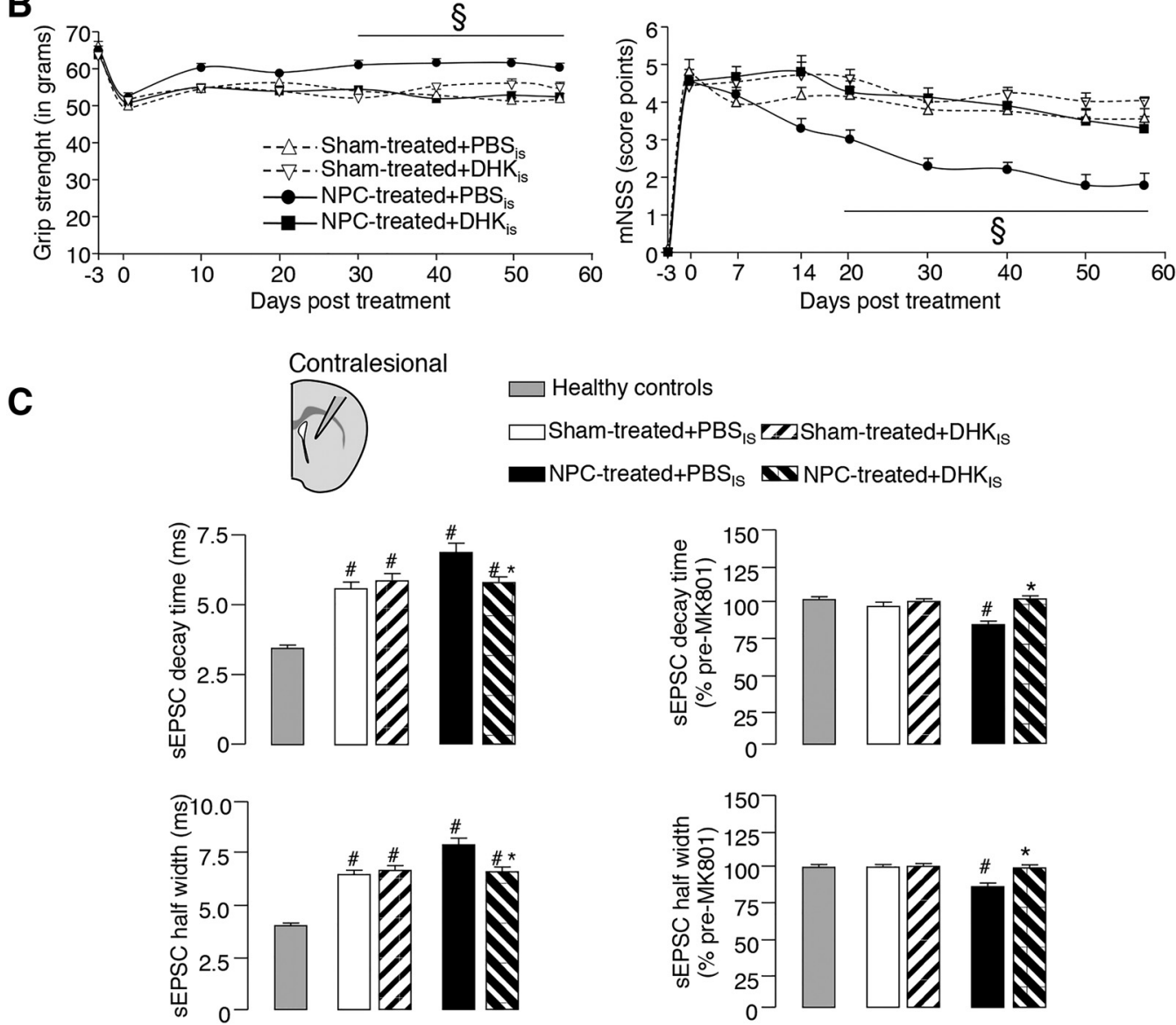

Figure 7. GLT-1 inhibition in NPC-treated ischemic mice prevents functional amelioration. $A$, Timeline depicting the experimental design to block the overexpression of GLT-1 in NPC-treated mice. $B$, Grip strength test of the lesion-contralateral paretic forepaw and mNSS test showing over time progressive functional neurological improvement only in NPC-treated mice receiving intrastriatal $\left.{ }_{15}\right)$ PBS (NPC $+\mathrm{PBS}_{15}$, black circle, $n=10$ mice) compared with NPC-treated mice receiving DHK (NPC + DHK ${ }_{15}$, black square, $n=11$ mice) and sham-treated mice treated either with intrastriatal PBS (PBS + $\mathrm{PBS}_{\mathrm{IS}}$, white up triangle, $n=5$ mice) or DHK (PBS + DHK is white down triangle, $n=10$ mice). ${ }^{\S} p \leq 0.05$ (two-way ANOVA, Bonferroni post hoc test). C, Neurophysiological properties of sEPSCs recorded from contralesional striatal neurons after MCAO at $14 \mathrm{dpt}$. The effects of DHK injection in sham- and NPC-treated ischemic mice are shown. DHK injection blocked the NPC-induced increase of SEPSC duration and the NPC-induced sensitivity to NMDA antagonist MK801. ${ }^{*} p \leq 0.05$ versus PBS IS -treated (one-way ANOVA, Tukey HSD). ${ }^{\#} p \leq 0.05$ versus healthy control (one-way ANOVA, Tukey HSD). $n=10-15$ per group per condition. Data are mean \pm SEM.

released from transplanted NPCs by intralesional injection of a neutralizing VEGF antibody in stroke mice (Wuest and Carr, 2010). NPC transplanted ischemic mice treated with VEGF neutralizing antibody displayed no neurological recovery compared with NPC-treated mice receiving the isotype antibody. Accordingly, at $10 \mathrm{dpt}$, overexpression of GLT-1 in peri-ischemic astrocytes induced by NPC treatment was reduced after anti-VEGF treatment (Fig. 9F, G).

These results suggest that NPC-mediated GLT-1 upregulation on astrocytes after stroke is at least partly VEGF-dependent and that GLT-1 on endogenous astrocytes contributes to the poststroke neurological recovery observed in NPC-transplanted mice.

\section{Discussion}

The neurological sequelae occurring after stroke are due to the disruption of brain connectivity occurring as a consequence of neuronal damage and of the impairment of compensatory plasticity processes (Johansson, 2000). Indeed, axonal degeneration is invariably seen not only within the lesion site but also in remote brain structures that have neuroanatomical links with the ischemic area (Thomalla et al., 2004; Crofts et al., 2011; Sist et al., 2012). Recovery from stroke is thus very much dependent on the possibility of developing treatments able not only to halt the neurodegenerative process (Zhang et al., 2012) but also to foster adaptive tissue plasticity via the involvement of uninjured cerebral regions from both hemispheres (Murphy and Corbett, 2009). Whatever is the therapeutic target in stroke, correct timing is of crucial importance. Indeed, after stroke a limited critical time-span of augmented neuroplasticity becomes evident (Krakauer et al., 2012; Wahl et al., 2014). The emergence of this time-constrained plasticity 

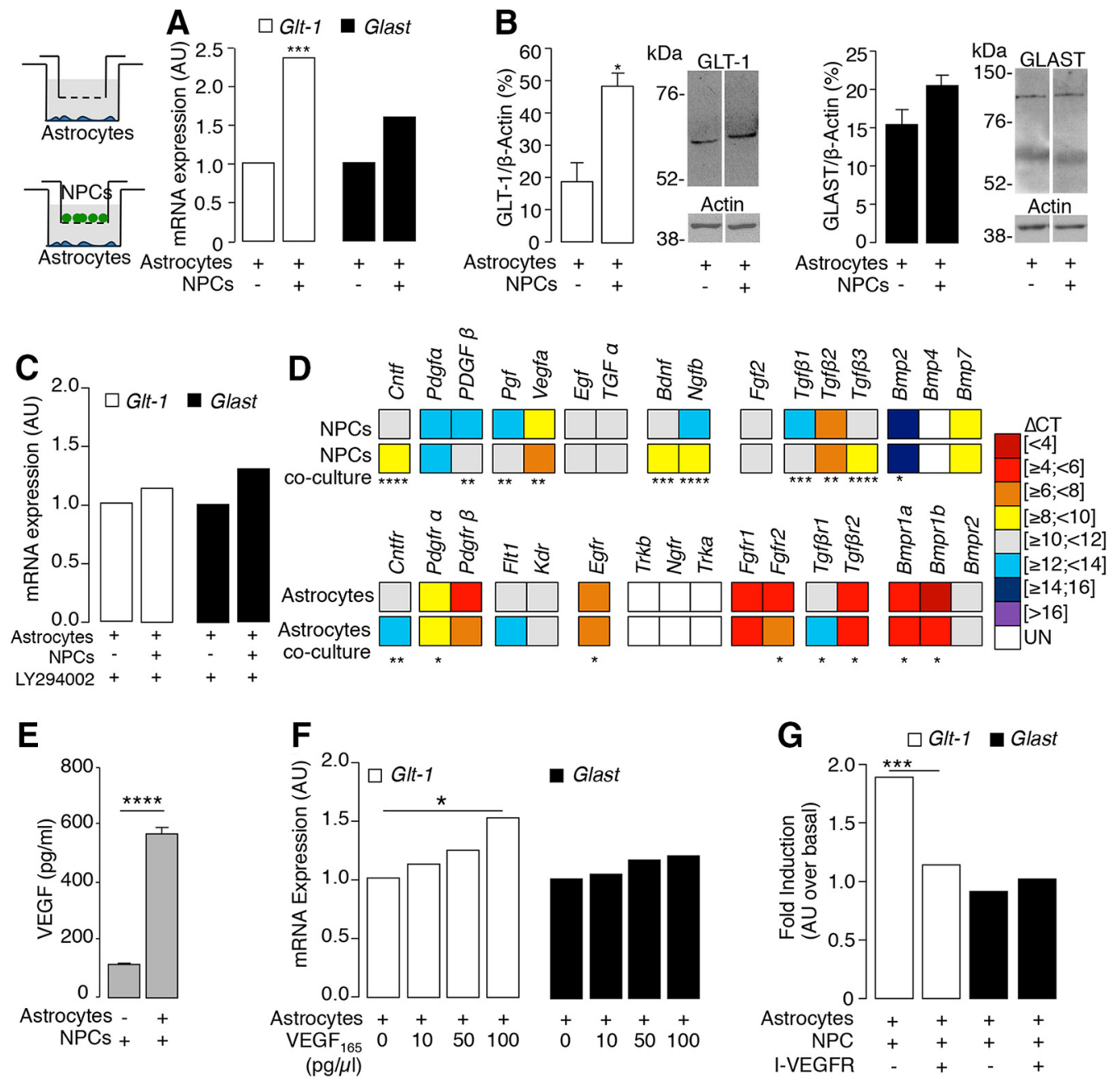

Figure 8. NPCs induce GLT-1 expression on astrocytes through the secretion of VEGF. Representation of the coculture setup: $5 \times 10^{4}$ astrocytes (blue) are plated in the bottom well for $24 \mathrm{~h}$ either alone or in coculture with $3 \times 10^{5} \mathrm{NPCs}$ (green) seeded in the transwell. GLT-1 and GLAST expression evaluated on astrocytes alone or after coculture at $(\boldsymbol{A}) \mathrm{mRNA}$ and $(\boldsymbol{B})$ protein level. C, Quantification of GIt- 1 and Glast mRNA expression on astrocytes alone or after coculture with NPCs after PI3 kinase inhibitor LY294002 (10 $\mu \mathrm{m}$ ) treatment. D, The color-coded heatmaps represent the expression profile of selected growth factors on NPCs (top lanes) and of its receptors on astrocytes (bottom lanes) either alone or after coculture. Data are represented as $\Delta C \mathrm{Ct}$ over GAPDH (note that a high $\Delta \mathrm{Ct}$, displayed as colder colors, denotes a low expression profile). UN, Undetermined (white). Asterisks indicate the statistical significance by comparing monocultured to cocultured cells. $\boldsymbol{E}$, ELISA for VEGF protein performed on cell medium derived from either NPCS alone or after coculture with astrocytes. $\boldsymbol{F}$, Evaluation of Glt- 1 and Glast expression at mRNA level on astrocytes after treatment with recombinant VEGF at increasing concentrations. G, Addition of the VEGF receptor inhibitor (676489, VEGFR2 kinase inhibitor IV, $500 \mathrm{~nm}, \mathrm{I}$-VEGFR) to astrocyte-NPC coculture inhibits Glt-1 upregulation on astrocytes. White bars represent GLT-1 expression. Black bars represent GLAST expression. $\boldsymbol{B}, \boldsymbol{E}$, Data are expressed as mean $\pm S E M$. $\boldsymbol{A}, \boldsymbol{C}, \boldsymbol{F}, \boldsymbol{G}$, Data are in arbitrary units (AU). $A, B, E, F, G$, One of $2-5$ independent experiments with $n=3-6$ replicates per group. ${ }^{*} p \leq 0.05$ (unpaired $t$ test). ${ }^{* *} p \leq 0.01$ (unpaired $t$ test). ${ }^{* * *} p \leq 0.001$ (unpaired $t$ test). ${ }^{* * *} p \leq 0.0001$ (unpaired $t$ test).

period seems to rely on transient modifications in gene and protein assemblages and neuronal excitability that resemble in part developmental patterns normally absent or present only at very low levels in the adult brain (Johansson, 2000; Carmichael et al., 2005). Too early as well as too late interventions might prove detrimental on plasticity: on the one hand, it has been recently shown that inhibition of $\alpha 5-\mathrm{GABA}_{\mathrm{A}}$ receptors or very early mobilization therapy, performed within $24 \mathrm{~h}$ after stroke, is rather detrimental (Clarkson et al., 2010; Bernhardt et al., 2015). On the other hand, too delayed interventions, such as rehabilitation, is also less effectual in promoting recovery (Paolucci et al., 2000).

Transplanted NPCs remain undifferentiated while promoting tissue recovery

Here we report the results of NPC transplantation into MCAO mice $3 \mathrm{~d}$ after stroke, a time-point that has been shown to be advantageous not only to cogently foster neuroplasticity processes but also to promote long-term survival of the transplanted cells (Clarkson et al., 2010; Darsalia et al., 2011). Indeed, we observed that NPC treatment is efficacious in promoting longlasting functional recovery up to $60 \mathrm{~d}$ after stroke. The recovery was accompanied by a reduction of the stroke-related degeneration of the ipsilesional CST and by the bilateral increase of the dendritic arborization of pyramidal neurons that was paralleled by a surge of axonal sprouting in the contralesional CST. We tend to exclude that the beneficial effects we have observed might result transient since it appeared $20 \mathrm{~d}$ after cell transplantation and persisted up to 2 months, the later time-point analyzed.

It has been reported that transplanted NPCs do exert their therapeutic potential in stroke via a multimodal mechanism of action (Bliss et al., 2007; Bacigaluppi et al., 2008). On one hand, NPCs might promote neuroprotection via a bystander-like mode of action based on undifferentiated NPCs releasing immuno- 

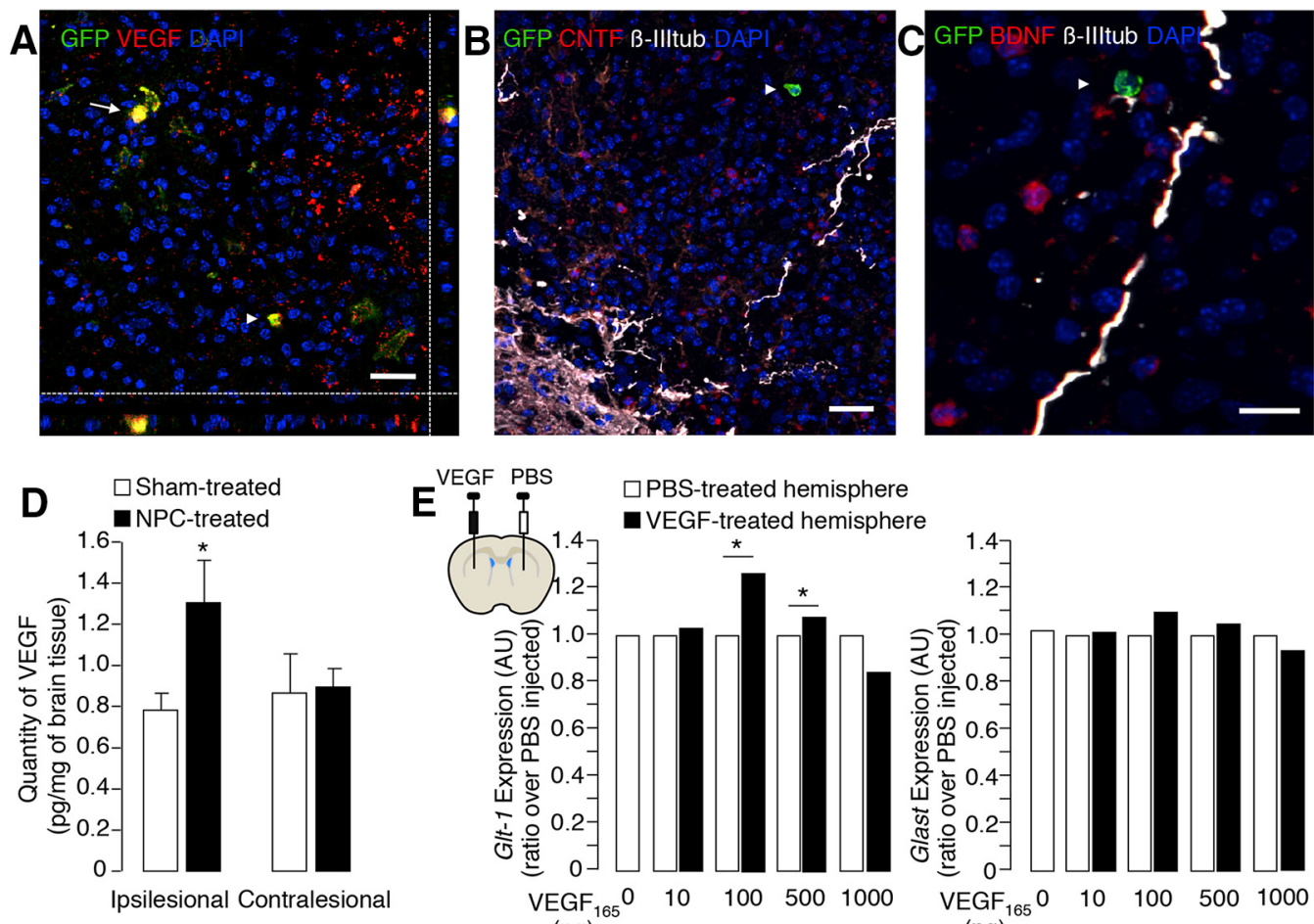

(pg)
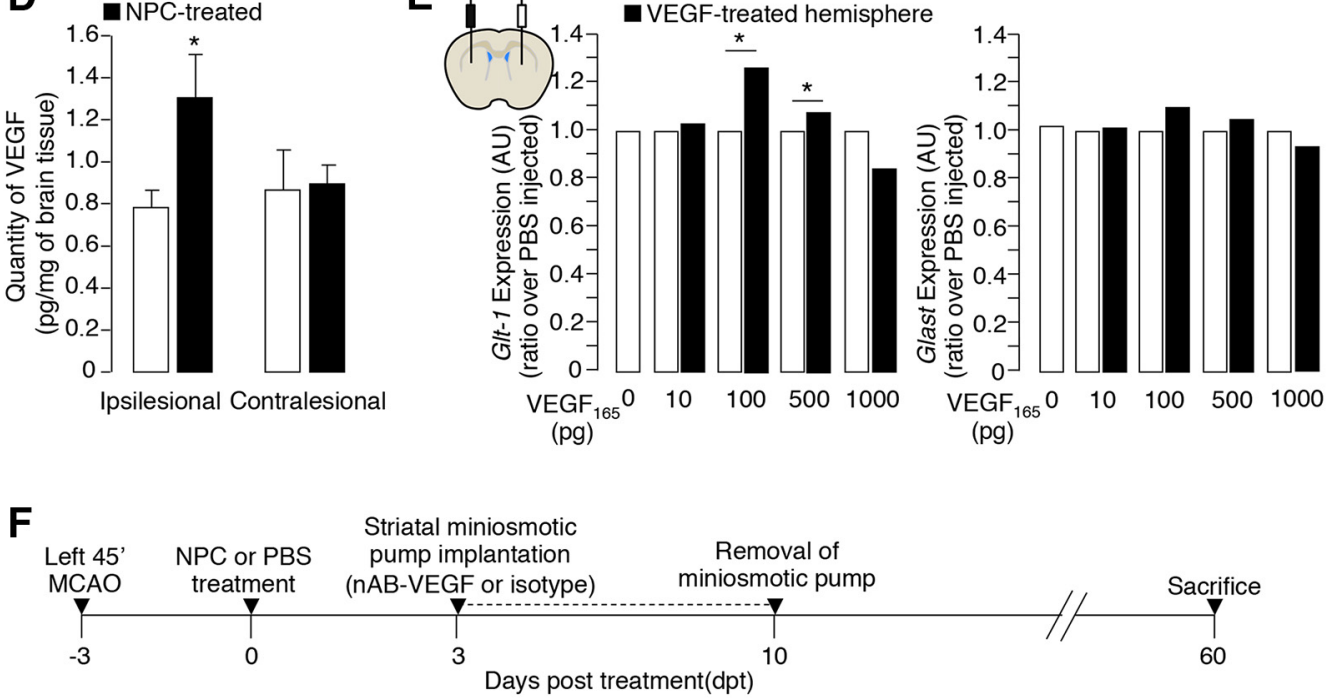

Functional tests (mNSS and GS test)

Histological analysis
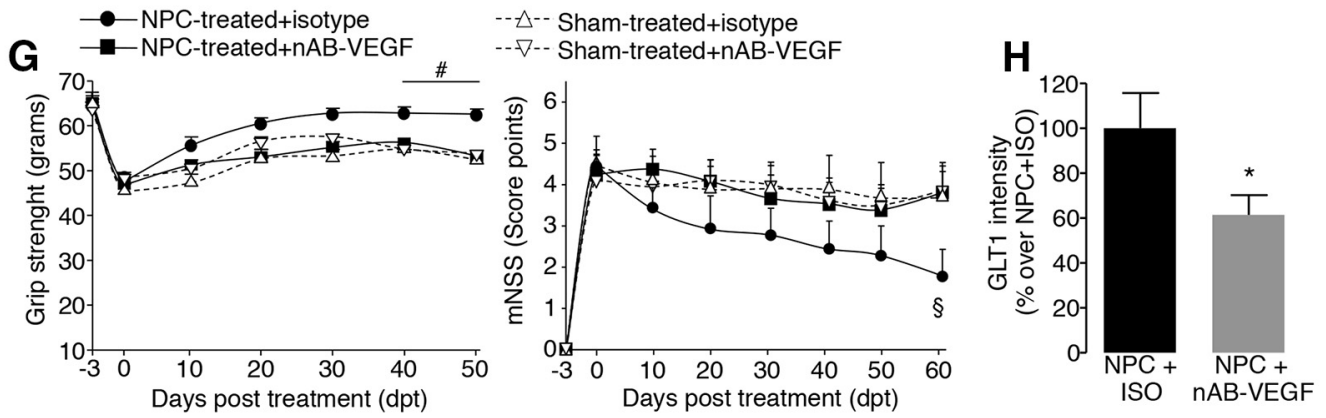

Figure 9. VEGF secretion by transplanted NPCs is necessary for GLT-1 upregulation and neurological recovery. $\boldsymbol{A}-\boldsymbol{C}$, Transplanted GFP ${ }^{+} \mathrm{NPCS}$ (green, arrowhead) were found to be strongly positive for VEGF (red in $\boldsymbol{A}$ ), but not for CNTF or BDNF (CNTF, red in $\boldsymbol{B}, \mathrm{BDNF}$, red in $\boldsymbol{C}$ ). $\boldsymbol{A}$, The cell denoted with the arrow is also shown in its $x-Z$ (lower edge) and $y-z$ (right edge) projection, separated by the dashed line. $\boldsymbol{B}, \boldsymbol{C}, \beta I I I-$ tubulin axons are stained in white. Nuclei are counterstained by DAPI (blue). Scale bar, $25 \mu \mathrm{m}$. $\boldsymbol{D}$, Quantification by ELISA of VEGF present in the ipsilesional and contralesional hemisphere of sham-treated and NPC-treated ischemic mice ( $n=8$ or 9 animals per group) at $10 \mathrm{dpt}$ (sham or NPC treatment at $3 \mathrm{~d}$ after ischemia). $\boldsymbol{E}$, Stereotactic injection of VEGF, but not of its diluent (PBS), in the striatum, enhances Glt- 1 expression, while not affecting Glast. Glt- 7 expression in mice injected with VEGF ( $2 \mu$ l into the left striatum, black bars) and with PBS ( $2 \mu$ l in the right striatum, white bars) $3 \mathrm{~d}$ after the injections (ratio of VEGF injected hemisphere over PBS injected hemisphere, $n=$ 3 or 4 animals). $F$, Timeline depicting the experimental design to block the beneficial effect of NPC-secreted VEGF. A group of mice was subjected to histology at $10 \mathrm{dpt}$, whereas another group continued behavioral tests up to $60 \mathrm{~d}$ post-transplantation. G, Grip strength test and mNSS showing functional neurological improvement only in NPC-treated mice receiving the isotype antibody (NPC + ISO, black circle, $n=6$ mice) compared with NPC-treated mice receiving VEGF neutralizing antibody (NPC + nAB-VEGF, black square, $n=7$ mice), sham-treated mice either treated with isotype (PBS + ISO, white up triangle, $n=4$ mice), or VEGF neutralizing antibody (PBS + nAB-VEGF, white down triangle, $n=8$ mice). $\boldsymbol{H}$, Quantification of GLT-1 protein expression in the peri-ischemic tissue at $10 \mathrm{dpt}$ revealed that increase of GLT-1 induced by NPC-treated with isotype is significantly reduced in mice treated with NPC plus the VEGF neutralizing antibody ( $n=4-6$ mice/group). $\boldsymbol{A}, \boldsymbol{D}, \boldsymbol{E}$, Data are mean \pm SEM. $\boldsymbol{B}$, Data are in arbitrary units (AU). ${ }^{*} p \leq 0.05$ ( $t$ test). ${ }^{\S} p \leq 0.05$ (Dunn multiple comparison test). ${ }^{\#} p \leq$ 0.05 (two-way ANOVA, Bonferroni post hoc test). 
modulatory and neurotrophic molecules (Jiang et al., 2006; Bacigaluppi et al., 2009; Andres et al., 2011; Hermann and Chopp, 2012). On the other hand, transplanted NPCs might directly contribute to replace damaged neurons in stroke once fully differentiated in vivo (Oki et al., 2012; Tornero et al., 2013). While conclusive data concerning the cellular and molecular mechanisms sustaining the NPC-mediated therapeutic effects in vivo are still lacking, this mode of action, namely "therapeutic plasticity" (Martino and Pluchino, 2006), has been shown to be associated with neuroinflammatory conditions. A bystander NPC-mediated effect has been, indeed, shown also in experimental multiple sclerosis (Pluchino et al., 2003, 2005; Laterza et al., 2013) and spinal cord injury (Cusimano et al., 2012). Here, we found that transplanted cells, localized within the ischemic and peri-infarct area, maintained for long-term a prevalently undifferentiated phenotype. This finding prompted us to hypothesize that a soluble factor released by undifferentiated NPCs might be involved in sustaining the therapeutic effect observed.

\section{NPC transplantation influences the excitatory-inhibitory neurophysiological balance}

Because functional recovery involves changes in neuronal excitability altering the cerebral representation of sensory-motor functions (Murphy and Corbett, 2009; Clarkson et al., 2010), we chose a time-point of $10 \mathrm{~d}$ after ischemia, a stage when the clinical amelioration begins, to study the neurophysiological characteristics of ipsilesional and contralesional striatal MSNs that are involved in corticostriatal transmission during plastic rearrangements (Centonze et al., 2007). We found that NPC treatment of ischemic mice partly preserved the inhibitory electrophysiological circuit in the ischemic hemisphere. Although intraparenchymal transplantation of inhibitory neurons has been shown to reshape the ocular dominance plasticity of the visual cortex after the critical period by integrating into existing neuronal circuits (Southwell et al., 2010), in our study, transplanted NPCs mainly persisted undifferentiated in the ischemic and peri-ischemic tissue. We thus hypothesized that interhemispheric fibers of the ipsilesional hemisphere might exert a milder inhibitory tone on the contralesional hemisphere, and this phenomenon could possibly lead to an increased contralesional excitatory activity (Mohajerani et al., 2011). Consistently, we found an enhanced contralesional postsynaptic potentiation of sEPSCs after NPC transplantation due to the modulation of NMDA receptors. The upregulation of NMDA receptors and the inadequacy of GABAergic transmission, found in the contralesional hemisphere of NPC-treated mice, might lower the threshold for long-term potentiation as previously described (Hagemann et al., 1998). We confirmed that this was the case in our setting because we measured an increased NMDAR/AMPAR ratio in NPC-treated mice in the contralesional hemisphere that reinforced the evidence for an enhanced synaptic strength. These changes do not rule out the possibility that further modifications in the transmitter release mechanisms may be modulated by MCAO because increased activity of presynaptic NMDA receptors was recorded (Centonze et al., 2007). These findings support the idea that the NPCmediated effect might have been capable per se of modifying locally (in the ipsilesional hemisphere) and then globally (in the contralesional hemisphere), the excitatory-inhibitory balance.

Glutamate transporters sustain the therapeutic effect of NPCs The rescuing of the inhibitory-excitatory balance as well as the relative low number of transplanted undifferentiated NPCs localizing in the ipsilesional hemisphere were rather suggestive for an indirect therapeutic effect. Thus, we concentrated our attention on the glutamate regulatory pathways. We found reduced extracellular glutamate levels in NPC-treated mice compared with controls. Furthermore, we observed an increased expression of GLT-1 on host astrocyte NPC-treated mice, a finding that might have contributed to partly ameliorating the deranged EAAT expression of the ischemic tissue (Rao et al., 2001).

The alteration of GLT-1 expression upon ischemia is considered one of the reasons for the neurotoxic effect of glutamate after stroke (Rao et al., 2001). Glutamate transporters have been previously described to regulate plasticity in a critical time window of development promoting activity-dependent remodeling (Takasaki et al., 2008). Accordingly, overexpression of GLT-1 per se, by adeno-associated viral vectors in neurons and astrocytes (Harvey et al., 2011) or by the delivery of ceftriaxone (a known antibiotic drug able to upregulate GLT-1), was shown to ameliorate ischemic damage (Rothstein et al., 2005; Chu et al., 2007). Furthermore, a polymorphism in the EAAT2 promoter, leading to higher plasma glutamate concentrations, has been associated with a higher frequency of nonresolving progressive human stroke (Mallolas et al., 2006). To better understand the relevance of this observation, we thus selectively inhibited GLT-1 functioning by dihydrokainate (Pines et al., 1992) and observed that the NPC-mediated neurological recovery and the synaptic strength enhancement of contralesional MSNs were reduced.

\section{VEGF mediates the therapeutic effect of NPCs}

We next investigated the "soluble" factor(s) that might be responsible for the NPC-mediated stroke recovery and increased expression of GLT-1 on peri-infarct endogenous astrocytes. We found in vitro that NPCs are able to upregulate GLT-1 on astrocytes and that this effect might be mediated by VEGF that is released by NPCs. Upregulation of Glt-1 on astrocytes after NPC coculture was blocked by treating the cells with LY294002, an inhibitor of PI3-K (Figiel et al., 2003; Wu et al., 2010), a molecule that along with Akt is one of the major effectors of VEGF signaling. In vivo, we found increased VEGF levels in the ipsilesional hemisphere where transplanted NPCs selectively localize. Indeed, in vivo VEGF neutralization abolished GLT-1 upregulation on endogenous astrocytes and restrained clinical recovery due to NPC treatment.

How VEGF might mediate in the peri-infarct area GLT-1 upregulation, either through a cell direct or cell indirect effect (e.g., through increasing survival of neurons which then might trigger the glial glutamate transporter on astrocytes), has still to be fully elucidated. Nevertheless, the proplasticity effect of VEGF is not entirely unexpected. Our results do, indeed, support previous work showing that intracerebroventricular injection of VEGF in experimental stroke favors both ipsilesional and contralesional neuronal plasticity and functional stroke recovery (Reitmeir et al., 2012). Moreover, VEGF has been indeed demonstrated to favor long-term potentiation and neuronal plasticity in the hippocampus of wild-type mice (Licht et al., 2011).

In conclusion, we show that NPC transplantation in ischemic stroke improves plasticity processes by restoring partly the electrical interhemispheric balance. This was because transplanted NPCs proved capable of increasing the uptake of peri-ischemic extracellular glutamate through the release of VEGF that, in turn, upregulated GLT-1 expression on endogenous astrocytes. Our results support the concept that strategies able to influence the electrical balance in a spatially targeted manner might result particularly suited to favor poststroke recovery. 


\section{References}

Andres RH, Horie N, Slikker W, Keren-Gill H, Zhan K, Sun G, Manley NC, Pereira MP, Sheikh LA, McMillan EL, Schaar BT, Svendsen CN, Bliss TM, Steinberg GK (2011) Human neural stem cells enhance structural plasticity and axonal transport in the ischaemic brain. Brain 134:1777-1789. CrossRef Medline

Bacigaluppi M, Pluchino S, Martino G, Kilic E, Hermann DM (2008) Neural stem/precursor cells for the treatment of ischemic stroke. J Neurol Sci 265:73-77. CrossRef Medline

Bacigaluppi M, Pluchino S, Peruzzotti-Jametti L, Kilic E, Kilic U, Salani G, Brambilla E, West MJ, Comi G, Martino G, Hermann DM (2009) Delayed post-ischaemic neuroprotection following systemic neural stem cell transplantation involves multiple mechanisms. Brain 132:2239-2251. CrossRef Medline

Bavelier D, Levi DM, Li RW, Dan Y, Hensch TK (2010) Removing brakes on adult brain plasticity: from molecular to behavioral interventions. J Neurosci 30:14964-14971. CrossRef Medline

Bernhardt J, Langhorne P, Lindley RI, Thrift AG, Ellery F, Collier J, Churilov L, Moodie M, Dewey H, Donnan G (2015) Efficacy and safety of very early mobilisation within $24 \mathrm{~h}$ of stroke onset (AVERT): a randomised controlled trial. Lancet 386:46-55. CrossRef Medline

Bliss T, Guzman R, Daadi M, Steinberg GK (2007) Cell transplantation therapy for stroke. Stroke 38:817-826. CrossRef Medline

Brown CE, Wong C, Murphy TH (2008) Rapid morphologic plasticity of peri-infarct dendritic spines after focal ischemic stroke. Stroke 39: 1286-1291. CrossRef Medline

Butti E, Bacigaluppi M, Rossi S, Cambiaghi M, Bari M, Cebrian Silla A, Brambilla E, Musella A, De Ceglia R, Teneud L, De Chiara V, D'Adamo P, Garcia-Verdugo JM, Comi G, Muzio L, Quattrini A, Leocani L, Maccarrone M, Centonze D, Martino G (2012) Subventricular zone neural progenitors protect striatal neurons from glutamatergic excitotoxicity. Brain 135:3320-3335. CrossRef Medline

Carmichael ST, Archibeque I, Luke L, Nolan T, Momiy J, Li S (2005) Growth-associated gene expression after stroke: evidence for a growthpromoting region in peri-infarct cortex. Exp Neurol 193:291-311. CrossRef Medline

Ceglia I, Carli M, Baviera M, Renoldi G, Calcagno E, Invernizzi RW (2004) The 5-HT receptor antagonist M100,907 prevents extracellular glutamate rising in response to NMDA receptor blockade in the mPFC. J Neurochem 91:189-199. CrossRef Medline

Centonze D, Saulle E, Pisani A, Bernardi G, Calabresi P (2001) Adenosinemediated inhibition of striatal GABAergic synaptic transmission during in vitro ischaemia. Brain 124:1855-1865. CrossRef Medline

Centonze D, Rossi S, Tortiglione A, Picconi B, Prosperetti C, De Chiara V, Bernardi G, Calabresi P (2007) Synaptic plasticity during recovery from permanent occlusion of the middle cerebral artery. Neurobiol Dis 27: 44-53. CrossRef Medline

Cheng MY, Wang EH, Steinberg GK (2014) Optogenetic approaches to study stroke recovery. ACS Chem Neurosci 5:1144-1145. CrossRef Medline

Chu K, Lee ST, Sinn DI, Ko SY, Kim EH, Kim JM, Kim SJ, Park DK, Jung KH, Song EC, Lee SK, Kim M, Roh JK (2007) Pharmacological Induction of ischemic tolerance by glutamate transporter-1 (EAAT2) upregulation. Stroke 38:177-182. CrossRef Medline

Clarkson AN, Huang BS, Macisaac SE, Mody I, Carmichael ST (2010) Reducing excessive GABA-mediated tonic inhibition promotes functional recovery after stroke. Nature 468:305-309. CrossRef Medline

Coleman PD, Riesen AH (1968) Environmental effects on cortical dendritic fields: I. Rearing in the dark. J Anat 102:363-374. Medline

Colombo E, Cordiglieri C, Melli G, Newcombe J, Krumbholz M, Parada LF, Medico E, Hohlfeld R, Meinl E, Farina C (2012) Stimulation of the neurotrophin receptor TrkB on astrocytes drives nitric oxide production and neurodegeneration. J Exp Med 209:521-535. CrossRef Medline

Corbett D, Giles T, Evans S, McLean J, Biernaskie J (2006) Dynamic changes in CA1 dendritic spines associated with ischemic tolerance. Exp Neurol 202:133-138. CrossRef Medline

Crofts JJ, Higham DJ, Bosnell R, Jbabdi S, Matthews PM, Behrens TE, Johansen-Berg H (2011) Network analysis detects changes in the contralesional hemisphere following stroke. Neuroimage 54:161-169. CrossRef Medline

Cusimano M, Biziato D, Brambilla E, Donegà M, Alfaro-Cervello C, Snider S, Salani G, Pucci F, Comi G, Garcia-Verdugo JM, De Palma M, Martino G, Pluchino S (2012) Transplanted neural stem/precursor cells instruct phagocytes and reduce secondary tissue damage in the injured spinal cord. Brain 135:447-460. CrossRef Medline

Darsalia V, Allison SJ, Cusulin C, Monni E, Kuzdas D, Kallur T, Lindvall O, Kokaia Z (2011) Cell number and timing of transplantation determine survival of human neural stem cell grafts in stroke-damaged rat brain. J Cereb Blood Flow Metab 31:235-242. CrossRef Medline

Domercq M, Etxebarria E, Pérez-Samartín A, Matute C (2005) Excitotoxic oligodendrocyte death and axonal damage induced by glutamate transporter inhibition. Glia 52:36-46. CrossRef Medline

Figiel M, Maucher T, Rozyczka J, Bayatti N, Engele J (2003) Regulation of glial glutamate transporter expression by growth factors. Exp Neurol 183: 124-135. CrossRef Medline

Hagemann G, Redecker C, Neumann-Haefelin T, Freund HJ, Witte OW (1998) Increased long-term potentiation in the surround of experimentally induced focal cortical infarction. Ann Neurol 44:255-258. CrossRef Medline

Harvey BK, Airavaara M, Hinzman J, Wires EM, Chiocco MJ, Howard DB, Shen H, Gerhardt G, Hoffer BJ, Wang Y (2011) Targeted overexpression of glutamate transporter 1 (GLT-1) reduces ischemic brain injury in a rat model of stroke. PLoS One 6:e22135. CrossRef Medline

Hermann DM, Chopp M (2012) Promoting brain remodelling and plasticity for stroke recovery: therapeutic promise and potential pitfalls of clinical translation. Lancet Neurol 11:369-380. CrossRef Medline

Invernizzi RW, Di Giovanni G, Di Matteo VP (2013) Microdialysis techniques in neuroscience. Totowa, NJ: Humana.

Jiang Q, Zhang ZG, Ding GL, Silver B, Zhang L, Meng H, Lu M, PourabdillahNejed-D S, Wang L, Savant-Bhonsale S, Li L, Bagher-Ebadian H, Hu J, Arbab AS, Vanguri P, Ewing JR, Ledbetter KA, Chopp M (2006) MRI detects white matter reorganization after neural progenitor cell treatment of stroke. Neuroimage 32:1080-1089. CrossRef Medline

Johansson BB (2000) Brain plasticity and stroke rehabilitation: the Willis lecture. Stroke 31:223-230. CrossRef Medline

Kidd FL, Isaac JT (2000) Glutamate transport blockade has a differential effect on AMPA and NMDA receptor-mediated synaptic transmission in the developing barrel cortex. Neuropharmacology 39:725-732. CrossRef Medline

Kirby ED, Kuwahara AA, Messer RL, Wyss-Coray T (2015) Adult hippocampal neural stem and progenitor cells regulate the neurogenic niche by secreting VEGF. Proc Natl Acad Sci U S A 112:4128-4133. CrossRef Medline

Krakauer JW, Carmichael ST, Corbett D, Wittenberg GF (2012) Getting neurorehabilitation right: what can be learned from animal models? Neurorehabil Neural Repair 26:923-931. CrossRef Medline

Laterza C, Merlini A, De Feo D, Ruffini F, Menon R, Onorati M, Fredrickx E, Muzio L, Lombardo A, Comi G, Quattrini A, Taveggia C, Farina C, Cattaneo E, Martino G (2013) iPSC-derived neural precursors exert a neuroprotective role in immune-mediated demyelination via the secretion of LIF. Nat Commun 4:2597. CrossRef Medline

Lepore AC, Rauck B, Dejea C, Pardo AC, Rao MS, Rothstein JD, Maragakis NJ (2008) Focal transplantation-based astrocyte replacement is neuroprotective in a model of motor neuron disease. Nat Neurosci 11:1294-1301. CrossRef Medline

Li Y, Lei Z, Xu ZC (2009) Enhancement of inhibitory synaptic transmission in large aspiny neurons after transient cerebral ischemia. Neuroscience 159:670-681. CrossRef Medline

Licht T, Goshen I, Avital A, Kreisel T, Zubedat S, Eavri R, Segal M, Yirmiya R, Keshet E (2011) Reversible modulations of neuronal plasticity by VEGF. Proc Natl Acad Sci U S A 108:5081-5086. CrossRef Medline

Mallolas J, Hurtado O, Castellanos M, Blanco M, Sobrino T, Serena J, Vivancos J, Castillo J, Lizasoain I, Moro MA, Dávalos A (2006) A polymorphism in the EAAT2 promoter is associated with higher glutamate concentrations and higher frequency of progressing stroke. J Exp Med 203:711-717. CrossRef Medline

Martino G, Pluchino S (2006) The therapeutic potential of neural stem cells. Nat Rev 7:395-406. CrossRef Medline

Martino G, Bacigaluppi M, Peruzzotti-Jametti L (2011) Therapeutic stem cell plasticity orchestrates tissue plasticity. Brain 134:1585-1587. CrossRef Medline

Masliah E, Mallory M, Alford M, DeTeresa R, Hansen LA, McKeel DW Jr, Morris JC (2001) Altered expression of synaptic proteins occurs early during progression of Alzheimer's disease. Neurology 56:127-129. CrossRef Medline

Mennerick S, Dhond RP, Benz A, Xu W, Rothstein JD, Danbolt NC, Isenberg 
KE, Zorumski CF (1998) Neuronal expression of the glutamate transporter GLT-1 in hippocampal microcultures. J Neurosci 18:4490-4499. Medline

Mohajerani MH, Aminoltejari K, Murphy TH (2011) Targeted ministrokes produce changes in interhemispheric sensory signal processing that are indicative of disinhibition within minutes. Proc Natl Acad Sci U S A 108:E183-E191. CrossRef Medline

Mosher KI, Andres RH, Fukuhara T, Bieri G, Hasegawa-Moriyama M, He Y, Guzman R, Wyss-Coray T (2012) Neural progenitor cells regulate microglia functions and activity. Nat Neurosci 15:1485-1487. CrossRef Medline

Murphy TH, Corbett D (2009) Plasticity during stroke recovery: from synapse to behaviour. Nat Rev 10:861-872. CrossRef Medline

Oki K, Tatarishvili J, Wood J, Koch P, Wattananit S, Mine Y, Monni E, Tornero D, Ahlenius H, Ladewig J, Brüstle O, Lindvall O, Kokaia Z (2012) Human-induced pluripotent stem cells form functional neurons and improve recovery after grafting in stroke-damaged brain. Stem Cells 30:1120-1133. CrossRef Medline

Ouyang YB, Voloboueva LA, Xu LJ, Giffard RG (2007) Selective dysfunction of hippocampal CA1 astrocytes contributes to delayed neuronal damage after transient forebrain ischemia. J Neurosci 27:4253-4260. CrossRef Medline

Paillé V, Picconi B, Bagetta V, Ghiglieri V, Sgobio C, Di Filippo M, Viscomi MT, Giampà C, Fusco FR, Gardoni F, Bernardi G, Greengard P, Di Luca M, Calabresi P (2010) Distinct levels of dopamine denervation differentially alter striatal synaptic plasticity and NMDA receptor subunit composition. J Neurosci 30:14182-14193. CrossRef Medline

Pannasch U, Vargová L, Reingruber J, Ezan P, Holcman D, Giaume C, Syková E, Rouach N (2011) Astroglial networks scale synaptic activity and plasticity. Proc Natl Acad Sci U S A 108:8467-8472. CrossRef Medline

Paolucci S, Antonucci G, Grasso MG, Morelli D, Troisi E, Coiro P, Bragoni M (2000) Early versus delayed inpatient stroke rehabilitation: a matched comparison conducted in Italy. Arch Phys Med Rehabil 81:695-700. CrossRef Medline

Papadopoulos CM, Tsai SY, Cheatwood JL, Bollnow MR, Kolb BE, Schwab ME, Kartje GL (2006) Dendritic plasticity in the adult rat following middle cerebral artery occlusion and Nogo-a neutralization. Cereb Cortex 16:529-536. CrossRef Medline

Paxinos G, Franklin KBJ (2000) The mouse brain in stereotaxic coordinates, Ed 2. San Diego: Academic.

Petr GT, Sun Y, Frederick NM, Zhou Y, Dhamne SC, Hameed MQ, Miranda C, Bedoya EA, Fischer KD, Armsen W, Wang J, Danbolt NC, Rotenberg A, Aoki CJ, Rosenberg PA (2015) Conditional deletion of the glutamate transporter GLT-1 reveals that astrocytic GLT-1 protects against fatal epilepsy while neuronal GLT-1 contributes significantly to glutamate uptake into synaptosomes. J Neurosci 35:5187-5201. CrossRef Medline

Pines G, Danbolt NC, Bjørås M, Zhang Y, Bendahan A, Eide L, Koepsell H, StormMathisen J, Seeberg E, Kanner BI (1992) Cloning and expression of a rat brain L-glutamate transporter. Nature 360:464-467. CrossRef Medline

Pluchino S, Quattrini A, Brambilla E, Gritti A, Salani G, Dina G, Galli R, Del Carro U, Amadio S, Bergami A, Furlan R, Comi G, Vescovi AL, Martino G (2003) Injection of adult neurospheres induces recovery in a chronic model of multiple sclerosis. Nature 422:688-694. CrossRef Medline

Pluchino S, Zanotti L, Rossi B, Brambilla E, Ottoboni L, Salani G, Martinello M, Cattalini A, Bergami A, Furlan R, Comi G, Constantin G, Martino G (2005) Neurosphere-derived multipotent precursors promote neuroprotection by an immunomodulatory mechanism. Nature 436:266-271. CrossRef Medline

Pluchino S, Muzio L, Imitola J, Deleidi M, Alfaro-Cervello C, Salani G, Porcheri C, Brambilla E, Cavasinni F, Bergamaschi A, Garcia-Verdugo JM, Comi G, Khoury SJ, Martino G (2008) Persistent inflammation alters the function of the endogenous brain stem cell compartment. Brain 131:2564-2578. CrossRef Medline

Proper EA, Hoogland G, Kappen SM, Jansen GH, Rensen MG, Schrama LH, van Veelen CW, van Rijen PC, van Nieuwenhuizen O, Gispen WH, de Graan PN (2002) Distribution of glutamate transporters in the hippocampus of patients with pharmaco-resistant temporal lobe epilepsy. Brain 125:32-43. CrossRef Medline
Rao VL, Bowen KK, Dempsey RJ (2001) Transient focal cerebral ischemia down-regulates glutamate transporters GLT-1 and EAAC1 expression in rat brain. Neurochem Res 26:497-502. CrossRef Medline

Reitmeir R, Kilic E, Reinboth BS, Guo Z, ElAli A, Zechariah A, Kilic U, Hermann DM (2012) Vascular endothelial growth factor induces contralesional corticobulbar plasticity and functional neurological recovery in the ischemic brain. Acta Neuropathol 123:273-284. CrossRef Medline

Rossi S, Prosperetti C, Picconi B, De Chiara V, Mataluni G, Bernardi G, Calabresi P, Centonze D (2006) Deficits of glutamate transmission in the striatum of toxic and genetic models of Huntington's disease. Neurosci Lett 410:6-10. CrossRef Medline

Rothstein JD, Patel S, Regan MR, Haenggeli C, Huang YH, Bergles DE, Jin L, Dykes Hoberg M, Vidensky S, Chung DS, Toan SV, Bruijn LI, Su ZZ, Gupta P, Fisher PB (2005) Beta-lactam antibiotics offer neuroprotection by increasing glutamate transporter expression. Nature 433:73-77. CrossRef Medline

Saal D, Dong Y, Bonci A, Malenka RC (2003) Drugs of abuse and stress trigger a common synaptic adaptation in dopamine neurons. Neuron 37:577-582. CrossRef Medline

Sist B, Jesudasan S, Winship IR (2012) Diaschisis, degeneration, and adaptive plasticity after focal ischemic stroke. In: Acute ischemic stroke (Garcia Rodríguez J, ed). Croatia: InTech. CrossRef

Southwell DG, Froemke RC, Alvarez-Buylla A, Stryker MP, Gandhi SP (2010) Cortical plasticity induced by inhibitory neuron transplantation. Science 327:1145-1148. CrossRef Medline

Takasaki C, Okada R, Mitani A, Fukaya M, Yamasaki M, Fujihara Y, Shirakawa T, Tanaka K, Watanabe M (2008) Glutamate transporters regulate lesion-induced plasticity in the developing somatosensory cortex. J Neurosci 28:4995-5006. CrossRef Medline

Tanaka K, Watase K, Manabe T, Yamada K, Watanabe M, Takahashi K, Iwama H, Nishikawa T, Ichihara N, Kikuchi T, Okuyama S, Kawashima N, Hori S, Takimoto M, Wada K (1997) Epilepsy and exacerbation of brain injury in mice lacking the glutamate transporter GLT-1. Science 276:1699-1702. CrossRef Medline

Thomalla G, Glauche V, Koch MA, Beaulieu C, Weiller C, Röther J (2004) Diffusion tensor imaging detects early Wallerian degeneration of the pyramidal tract after ischemic stroke. Neuroimage 22:1767-1774. CrossRef Medline

Tornero D, Wattananit S, Grønning Madsen M, Koch P, Wood J, Tatarishvili J, Mine Y, Ge R, Monni E, Devaraju K, Hevner RF, Brüstle O, Lindvall O, Kokaia Z (2013) Human induced pluripotent stem cell-derived cortical neurons integrate in stroke-injured cortex and improve functional recovery. Brain 136:3561-3577. CrossRef Medline

Ungless MA, Whistler JL, Malenka RC, Bonci A (2001) Single cocaine exposure in vivo induces long-term potentiation in dopamine neurons. Nature 411:583-587. CrossRef Medline

Wahl AS, Omlor W, Rubio JC, Chen JL, Zheng H, Schröter A, Gullo M, Weinmann O, Kobayashi K, Helmchen F, Ommer B, Schwab ME (2014) Neuronal repair: asynchronous therapy restores motor control by rewiring of the rat corticospinal tract after stroke. Science 344:1250-1255. CrossRef Medline

West MJ, Slomianka L, Gundersen HJ (1991) Unbiased stereological estimation of the total number of neurons in thesubdivisions of the rat hippocampus using the optical fractionator. Anat Rec 231:482-497. CrossRef Medline

Wu X, Kihara T, Akaike A, Niidome T, Sugimoto H (2010) PI3K/Akt/ mTOR signaling regulates glutamate transporter 1 in astrocytes. Biochem Biophys Res Commun 393:514-518. CrossRef Medline

Wuest TR, Carr DJ (2010) VEGF-A expression by HSV-1-infected cells drives corneal lymphangiogenesis. J Exp Med 207:101-115. CrossRef Medline

Yu X, Wang G, Gilmore A, Yee AX, Li X, Xu T, Smith SJ, Chen L, Zuo Y (2013) Accelerated experience-dependent pruning of cortical synapses in ephrin-A2 knockout mice. Neuron 80:64-71. CrossRef Medline

Zhang J, Zhang Y, Xing S, Liang Z, Zeng J (2012) Secondary neurodegeneration in remote regions after focal cerebral infarction: a new target for stroke management? Stroke 43:1700-1705. CrossRef Medline 